Qualifying Faults - The Role of Professionalism and Accountability in Bidding Procedures

Amos Schurr, Guilford Glazer Faculty of Business and Management, Ben-Gurion University of the Negev, Israel.

Omer Dekel, Weller - Dekel \& Co. Law Firm, Israel.

Margarita Leib, Amsterdam School of Economics, University of Amsterdam, Netherlands. Andrea Pittarello, Department of Psychology, Virginia Tech, USA.

Shaul Shalvi, Amsterdam School of Economics, University of Amsterdam.

Simone Moran, Guilford Glazer Faculty of Business and Management, Ben-Gurion University of the Negev, Israel.

Correspondence concerning this article should be addressed to Amos Schurr Guilford Glazer Faculty of Business and Management, Ben-Gurion University of the Negev, P.O.B. 653 Beer-

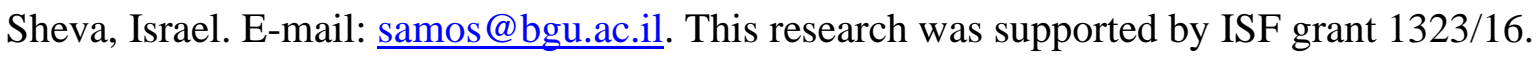




\title{
Qualifying Faults: The Role of Professionalism and Accountability in Bidding Procedures
}

\begin{abstract}
Competitive Bidding is the most common method used by organizations and governments to receive bids from prospective suppliers. Although the method is designed to ensure objectivity when considering proposals, here we suggest that it may be biased in favor of lower priced bids, a phenomenon termed lower bid bias (LBB). Importantly, we demonstrate that this bias leads people to qualify and choose bids that are faulty and should be outright rejected. We also provide insights into cognitive and attentional mechanisms underlying the bias, suggesting that it stems from intuitive information processing. This notion is supported by demonstrating that professionalism and process accountability moderate the bias, and by results we obtain when using eye-tracking methodology.
\end{abstract}




\section{Qualifying Faults: The Role of Professionalism and Accountability in Bidding Procedures}

Arthur Miller's acclaimed play “All My Sons" is based on the true story of a huge purchasing scandal: During World War II the US air force purchased defective aircraft engines from the Curtiss-Wright Aeronautical Corporation. The purchase resulted in the death of the 24-year-old pilot, Lieutenant John Andree Temple, and the consequent conviction and dismissal of several army officers. Whereas the play focuses on the seller's perspective stating, "it is all about nickels and dimes", here we examine the buyer's perspective. Specifically, we ask whether focusing on the (cheap) price may be a key factor in organizational decisions that result in the purchase of defective items or services.

Nowadays, to ensure an unbiased choice of the best supplier, governments, federal agencies, and large firms commonly use Competitive Bidding mechanisms for acquiring goods and services. Competitive Bidding mechanisms implement a transparent procurement process in which the customer first publishes the scope, specifications, terms and conditions of the proposed contract, as well as the bids' evaluation criteria, and then solicits bids from competing contractors, suppliers, or vendors. Such an approach seeks to stimulate competition and prevent favoritism. Competitive Biddings are ubiquitous, and in many organizations, almost all goods and services, from pencils to complex computer systems, are purchased using such a mechanism. US Federal Procurement Data System (2020), for example, reports that in 2018 alone, Competitive Bidding procedures of the top 100 contractors totaled some $\$ 305$ billion in federal expenditures. But to what extent do Competitive Biddings secure the choice of worthy rather than defective alternatives? Are they prone to evaluator's judgment errors? And if so, when and why? Most importantly perhaps, what is the psychological mechanism underlying such errors and how can these errors be mitigated? These are the questions we tackle. 


\section{Lower Bid Bias}

Although Competitive Biddings are designed to ensure that the best supplier is chosen in an unbiased manner, recent findings suggest that bid evaluators exhibit a Lower Bid Bias they tend to evaluate the quality of cheap bids in an exceedingly favorable manner (Dekel \& Schurr, 2014). In one of their experiments, for example, Dekel and Schurr asked 36 procurement officers - members of tender evaluation committees - to consider a competitive bidding procedure conducted by a municipality. Two bids were evaluated. One bid was qualitatively superior but also pricier than the other bid. The experiment followed the typical evaluation procedures used in such cases: The procurement officers received a table detailing the evaluation criteria for choosing the winning bid, the maximum quality points per criterion, and additional information provided by the bidders regarding each criterion. The officers scored the bids' qualitative criteria without being exposed to their respective prices. After four weeks, the officers followed the exact same procedure, but scored the criteria after they had been exposed to each bid's price. The procurement officers demonstrated a Lower Bid Bias. When the prices were known (compared to sealed), the procurement officers granted higher scores to the qualitative features of the cheaper (but qualitatively inferior) bids. An attractive (i.e., cheap) price painted the bid more favorably. Consequently, an objectively mediocre bid was considered superior when its (relatively) cheap price was revealed - violating the basic principle that price should not affect perceived quality in such procedures.

Here, we demonstrate that the Lower Bid Bias leads people not only to overvalue poor quality bids, but also to qualify and choose bids that are faulty and should be outright rejected. We further seek to gain insight into cognitive and attentional mechanisms underlying the Lower Bid Bias, testing whether the bias stems from intuitive information processing and can thus be mitigated under deliberative processing. To test this possibility, 
we compare laypeople to experienced procurement officers who are trained at making bidding decisions and thus may be less susceptible to making intuitively suboptimal decisions. Further, we use eye-tracking methodology to examine the attentional processes underlying the lower bid bias. Namely, the preference for low price over higher quality bids. Lastly, we explore the role of process accountability in mitigating the bias by shifting people to adopt a more deliberative processing style.

\section{Why does the Lower Bid Bias occur?}

Information is an essential part of making optimal choices. For example, it has been claimed that in typical decision problems "information never has a negative value to the decision-maker, at worst, irrelevant information can be ignored" (Milgrom \& Weber, 1982). In the context of bid evaluations, the principle of assessing as much information as possible, is commonly implemented via one-step evaluation procedures. In such procedures, all bids are evaluated jointly, side-by-side, with complete information regarding their qualitative components, as well as their price. Whereas exposing bid evaluators to complete information has its' merits, we suggest that exposing price and quality simultaneously may tint the qualitative evaluations of low-priced bids in an unjustifiably favorable light.

Several accounts may explain why exposing bid evaluators to complete information may result in a Lower Bid Bias. Human judgment is known to be bounded (March \& Simon, 1958; Simon, 1957), and people often rely on an intuitive decision-making processing style System 1 - rather than a deliberative and analytical style - System 2 (Kahneman, 2011; Sloman, 1996; Tversky \& Kahneman, 1974). A vast amount of follow-up work suggest that in order to deal with complex environments, decision-makers rely on numerous heuristics i.e., simplifying strategies or rules of thumb that provide efficient ways to cope with complexity (Bazerman \& Moore, 2012; Morewedge \& Kahneman, 2010; Northcraft \& Neale, 1987). Because people's cognitive capacity is limited, constraining their ability to fully attend 
and process information, people often (unconsciously and automatically) engage in information filtering - or focusing failures (Chugh, Bazerman, \& Banaji, 2005). Such failures relate to ignoring accessible and important information, while attending to equally accessible, yet irrelevant or less important information, corrupting decision quality (Bazerman \& Moore, 2012; Schkade \& Kahneman, 1998; Wilson, Wheatley, Meyers, Gilbert, \& Axsom, 2000). This idea is in-line with Fuzzy-Trace theory (Brainerd \& Reyna, 1990; Reyna, \& Brainerd, 1995), according to which when processing information, people have a tendency to extract its gist rather than the complete verbatim. Extracting the gist rather than attending to the complete verbatim exposes people to judgmental biases. Taken together, it seems that intuitive and heuristic processing style may cause bid evaluators who encounter excess information (i.e., both quality ranks and price) to over-focus on a subset of information (i.e., price).

We suggest that bid evaluators are likely to focus on the price, and favor cheap prices for two main reasons: (1) Most procurement processes are price oriented, whereby the buyers' key objective is to get the best possible deal, leading to a self-fulfilling choice distortion (DeKay, 2015), and (2) procurement evaluations are typically joint evaluation processes - i.e., comparative in nature. According to the distinction bias (Hsee \& Zhang, 2004), in such joint evaluations, differences with respect to quantitative values (such as prices), are easier to evaluate and thus more likely to impact judgement than differences with respect to the more difficult to compare qualitative attributes.

\section{The current investigation - Wrong intuitive decisions: comparing experts and laypeople}

Here, we examine the extent to which the Lower Bid Bias affects professionals versus laypeople's decisions to qualify faulty and questionable low priced bids. Faulty bids refer to bids that are clearly defective. Questionable bids refer to bids for which the extent of compliance with the competitive bidding requirements is debatable. From a practical 
perspective, studying differences between laypeople and professionals is important because in many organizations, laypeople, i.e., employees who are not specialized and trained as procurement officers, actually deal with procurement. Moreover, uncovering differences between experts and laypeople is of interest due to the high level of professionalism expected from bid evaluators. This includes the intricate set of evaluation criteria bid evaluators consider, the complexity of the transactions, and the variety of products and services they deal with, ranging from procuring simple off-the-shelf products (e.g., office supplies) and services (e.g., cleaning) to procuring complex products and services (e.g., IT systems, or infrastructure works). From a theoretical perspective, if laypeople's tendency to qualify low priced faulty bids stems from their biased, intuitive system-1 processing, then we expect the tendency to be attenuated among professionals. Thus, our first hypothesis is:

H1: Laypeople are more likely than professionals to qualify low priced faulty bids.

At first glance it might be conjectured that laypeople are more likely than professionals to qualify problematic bids, due to the formers' lack of knowledge - i.e., laypeople do not have sufficient domain-specific expertise to detect faults. However, the attenuated tendency of professionals (compared to laypeople) to qualify problematic bids, may be due to more than a mere effect of knowledge - namely, to differences in information processing by laypeople versus professionals. Indeed, past work on Naturalistic Decision Making (Zsambok \& Klein, 2014) and Fuzzy Trace Theory (Brainerd \& Reyna, 1990; Reyna, \& Brainerd, 1995; Reyna, 2012; Reyna, Chick, Corbin, \& Hsia, 2014), indicates that in their area of expertise, experts are less biased and more likely to make optimal decisions than laypeople (Chase \& Simon, 1973; Crandall \& Getchell-Reiter, 1993; De Groot, 1978; Gilovich, Griffin, \& Kahneman, 2002; Klein, Calderwood, \& Clinton-Cirocco, 1986). Typical examples include: (a) physicians and nurses who by merely looking at their patients, can infer the seriousness of their medical condition (Crandall \& Getchell-Reiter, 1993; Gawande, 2002; Groopman \& 
Prichard, 2007); (b) physicians with more domain-specific knowledge (e.g., cardiologists) who are better than medical students at discriminating levels of risk, require less information for diagnosing, and make sharper all-or-none distinctions among decision categories (Reyna \& Lloyd, 2006); (c) firefighters who can immediately notice signs that a house is going to collapse and anticipate the direction in which the flames will spread (Klein et al., 1986); and (d) chess masters who have the unusual ability to appreciate the dynamics of complex positions and quickly judge a line of play as promising or futile (Chase \& Simon, 1973). These findings imply that professional procurement officials are more likely than laypersons to detect faults and, consequently, to disqualify faulty bids.

We further assess the possibility that the laypeople's tendency to qualify low priced faulty bids stems from their reliance on intuitive system-1 processing style. To do so we employ eye-tracking methodology. Eye-tracking provides a non-obtrusive means to assess attention and information processing (e.g., Glöckner \& Herbold, 2011; Horstmann, Ahlgrimm, \& Glöckner, 2009; Hristova \& Grinberg, 2008; Innocenti, Rufa, \& Semmoloni, 2010; Just \& Carpenter, 1976; Russo \& Rosen, 1975; Russo, 1978; Russo \& Leclerc, 1994; Wang \& Spezio, ). Overall, there is converging evidence that the more attention people allocate to certain pieces of information, the more they weigh such information when making decisions (Fiedler, Glöckner, Nicklisch, \& Dickert, 2013; Glöckner, Fiedler, Hochman, Ayal, \& Hilbig, 2012; Halevy \& Chou, 2014; Krajbich \& Rangel, 2011). Additionally, recent work showed that people look at desirable information - information that they ultimately choose - early on during the decision process (Hochman, Glöckner, Fiedler, \& Ayal, 2016; Pittarello, Fratescu, \& Mathôt, 2019). Because eye movements occur outside conscious control, this research suggests that many preferences are driven by intuitive processes (see Pittarello et al., 2019).

This leads us to predict that: 
$\mathrm{H} 2$ : Overall, people will choose $(\mathrm{H} 2 \mathrm{a})$ and have longer fixations on $(\mathrm{H} 2 \mathrm{~b})$ the cheap option than at the more expensive option, even if the latter is superior quality-wise.

Further, if the preference for low-price over high quality bids is indeed intuitive, choosing the low-price bids should be faster, and therefore associated with less deliberation than choosing the high-quality bids. Here, we operationalize deliberation via examining the extent to which people shift their attention from one bid to the other, as manifested in their gaze transitions. This measure is a good proxy of information search and information acquisition (see Horstmann et al., 2009), meaning that a higher number of transitions indicates that participants are more carefully evaluating alternatives. Indeed, research has showed that people exhibit more transitions when they experience a decision conflict (Chua, Hannula, \& Ranganath, 2012).

In light of this evidence we predict that:

H3: Participants who choose the cheap option (compared to the better quality one), will exhibit longer fixations on the cheap option (H3a), faster decisions (H3b), and more gaze transitions between the two options $(\mathrm{H} 3 \mathrm{c})$.

\section{Mitigating the tendency to qualify problematic bids}

If as we propose here, laypeople's tendency to qualify low priced faulty bids stems from their intuitive heuristic-based judgment processes, rather than from a mere lack of knowledge, this tendency should be attenuated by interventions shifting laypeople to a more systematic mode of information processing. One way to achieve such a shift is to lead people to make more between-bid comparisons through the bids' presentation format. Differences in presentation format have been found to impact the preferred decision strategy and consequently actual choices (Bettman \& Kakkar, 1977; Erev, Shimonowitch, Schurr, \& Hertwig, 2007; Newell \& Simon, 1972; Russo \& Dosher, 1983). 
Another possible way to make people deliberate more is to institute process accountability (Lerner \& Tetlock, 1999; Tetlock, 1992) - the expectation that one's decisions will be judged according to the quality of the process used to arrive at the decision. Process accountability may be achieved by requiring people to explain their decisions. When people expect that they will have to explain their judgments, they typically engage in a more effortful, systematic, and self-critical (rather than intuitive) mode of processing (e.g., Ashton, 1992; De Dreu, Koole, \& Steinel, 2000; Lerner \& Tetlock, 1999; Tetlock, 1992). A prerequirement to justify decisions, often leads individuals to survey and pay attention to a wider range of cues, monitor the cues that are worthy of influencing their decisions, anticipate counter-arguments, weigh counter-arguments impartially, and engage in a more nuanced and normatively justifiable thought process (Brtek \& Motowidlo, 2002; Lerner \& Tetlock, 1999; Siegel-Jacobs \& Yates, 1996; Simonson \& Staw, 1992; Tetlock, Vieider, Patil, \& Grant, 2013). Thus, to the extent that qualifying low priced problematic bids stems from intuitive heuristic based decision-making processes, rather than from a mere lack of knowledge, process accountability should attenuate this tendency. Thus, our fourth hypothesis is:

H4: Laypeople's tendency to qualify low priced faulty bids will be attenuated under a more systematic mode of information processing. Specifically, inducing process accountability will reduce laypeople's tendency to qualify low priced problematic bids.

\section{Experiments Overview}

We conducted six experiments to investigate how price information affects the tendency of professional procurement officials and of laypeople to qualify problematic low priced bids. Experiment 1a emulated the first stage of a two-stage procedure in which bid evaluators inspected bids without price information and (dis)qualified them to pass to the second stage, in which price is revealed and the winning bid is chosen. This experiment served as a preliminary examination of the likelihood of detecting qualitative faults in the 
absence of price information. Experiment $1 \mathrm{~b}$ emulated a one-stage procedure, whereby bid evaluators inspect bids with all information, including price, and choose the winning bid, enabling an examination of the likelihood of detecting qualitative faults when price information is present. Experiment 2 systematically examined the extent to which price exposure affects professionals' and laypeople's tendency to qualify problematic low-priced bids. Experiments $3 \mathrm{a}$ and 3b, employed eye-tracking methodology. Experiment 3a measured participants' gazes, gaze transitions, and decision times to examine the extent to which people demonstrate an intuitive rather than deliberate preference for low priced options. Experiment $3 \mathrm{~b}$ corroborates the results obtained in Experiment $3 \mathrm{a}$ and further tests the extent to which the preference for low price bids is robust to presentation formats (i.e., highlighting between-bids or within-bids comparisons). Finally, Experiment 4 examined the role of process accountability in attenuating the tendency to qualify low priced problematic bids, by asking participants to explain their decisions (Lerner \& Tetlock, 1999).

\section{Experiments 1a and $1 \mathrm{~b}$ - Qualifying and choosing problematic bids}

Experiments 1a and 1b examined evaluators' decisions in two common types of bidding procedures - a two-stage (Experiment 1a) and a one-stage (Experiment 1b) procedure. In a two-stage procedure, at the first stage bid evaluators are exposed to all information about the submitted bids except price, which is revealed only at the second stage. The evaluators' task in the first stage is to inspect all bids and decide which should be disqualified and which should be qualified to pass to the second stage. In the second stage, prices of the bids still in the race are revealed, and the lowest priced bid is declared the winner. In contrast, in a one-stage procedure, bid evaluators are exposed at the outset to all information about the submitted bids, including price information. Evaluators' task is to inspect all bids and choose the winner. The key difference between the tasks in one- versus 
two-stage procedures is the presence vs. absence of price information when making decisions.

\section{Experiment 1a}

Experiment 1a simulated the first stage of a two-stage Competitive Bidding procedure. In line with the above-described procedure, prices were sealed and participants had to qualify the bids meeting the threshold requirements of a Competitive Bidding for the construction of a medical clinic.

\section{Method}

We sampled 23 undergraduate students and 35 public officials. The public officials all dealt with public procurement and Competitive Biddings in their everyday jobs and were recruited during a mid-career training program. Participants were asked to consider and evaluate four bids supposedly submitted to a Competitive Bidding for the construction of a pediatric oncology clinic. The bids' details and the Competitive Bidding prerequisites were presented in a tabular format on a sheet of paper (see Figure 1). Participants were asked to mark the bids that should pass to the second stage. The task was carried out individually (see Appendix).

Two of the four bids were problematic. Bid A was clearly defective since it did not meet a threshold requirement of employing a construction engineer with sufficient experience. No rational for the failure to meet the threshold requirements was provided. Bid B was questionable. Specifically, the bid specified having a physician who had residency in general oncology, instead of the required pediatric oncology. However, the bid did provide some rational for the deviation from threshold requirements, indicating that there were no residencies in pediatric oncology at that time. Bids C and D met the competitive bidding threshold requirements. Importantly, as in any two-stage competitive bidding procedure, the 
participants marked the bids that should pass on to the second stage without knowing their prices.

\section{Results}

The top panel of Figure 2 presents professional and laypeople's percentages of qualifying decisions for each bid. As can be seen, all participants qualified bids $\mathrm{C}$ and $\mathrm{D}$, which met the threshold requirements, indicating that all participants understood the task.

Our main interest, however, is in people's tendency to qualify problematic bids (i.e., A and B). To test the effect of professionalism on the tendency to approve questionable and faulty bids, we conducted two sets of comparisons. First, we examined the extent to which experts vs. laypeople could differentiate between the bids. Note that differentiating between bids is one aspect of professionalism, as questionable bids are not necessarily faulty.

A McNemar test comparing the qualifying proportions of the faulty vs. questionable bid within each group suggests that professionals were better than laypeople in differentiating between the faulty and the questionable bids. Professionals were less likely to qualify faulty bids $(9 \%)$ than questionable bids $(49 \% ; p=.001)$. In contrast, laypeople qualified faulty bids $(13 \%)$ to the same extent as they qualified questionable bids $(22 \% ; p=.687)$.

We next compare the qualifying proportions of each bid across groups. A Chi-square test revealed that whereas laypeople and professionals differed with respect to the likelihood of qualifying the questionable bid (22\% vs. $49 \%$ respectively, $\chi^{2}(1)=4.244, p=.039$, Cramer's $V=0.271$ ), they did not differ with respect to the likelihood of qualifying the faulty bid ( $13 \%$ vs. $9 \%$, respectively, $\chi^{2}(1)=.299, p=.584$, Cramer's $\left.\mathrm{V}=0.078\right)$. Taken together, results suggest that laypeople may be somewhat less capable than professionals to differentiate between faulty and questionable bids. Importantly, however, when price 
information is sealed, laypeople seem to be just as reluctant as professionals to qualify a clearly faulty bid, implying that they were able to identify the fault.

\section{Experiment 1b}

Experiment $1 \mathrm{~b}$ simulated an ordinary one-stage competitive bidding procedure. In a one-stage competitive bidding procedure, prices are revealed from the outset and bid evaluators choose the winning bid (see Figure 1).

\section{Method}

Thirty-one undergraduate students and 36 public officials who deal with public procurement and competitive biddings (and were undertaking a mid-career training program), participated in the experiment. Participants were asked to consider the same pediatric oncology clinic case that was presented in Experiment 1a. However, in contrast to Experiment 1a, the bids' prices were exposed from the outset, and participants were asked to choose the winning bid. Note that when choosing, participants were aware of the fact that the faulty bid - Bid A - was the cheapest ( $\$ 17.8$ million) and the questionable bid - Bid B - was the second cheapest (\$18.9 million). As in Experiment 1a, the bids were presented in a tabular format on a sheet of paper. The task was carried out individually (see Appendix).

\section{Results}

The bottom panel of Figure 1 presents professional and laypeople's choices. As in Experiment 1a, we compared choice proportions within and across groups. McNemar tests for comparing choice proportions of the faulty vs. questionable bids within each group suggest again that professionals were better than laypeople in differentiating between the faulty and questionable bids. The proportions of professionals choosing the faulty and questionable bids were $3 \%$ vs. $28 \%(p=.012)$, while the proportions of laypeople choosing 
the faulty and questionable bids were not significantly different from each other (26\% vs. $29 \%, p=.857)$.

Comparing choice proportions for each bid type between groups using Chi Square tests revealed that whereas laypeople and professionals were similar with respect to the likelihood of choosing the questionable bid as the winner $(26 \%$ vs. $28 \%$ respectively, $\chi 2(1)=$ $.033, \mathrm{p}=.856$, Cramer's $\mathrm{V}=0.02$ ), they differed with respect to the faulty bid. The proportion of laypeople choosing the faulty bid was significantly greater than the proportion of professionals choosing it $(29 \%$ vs. only $3 \%, \chi 2(1)=9.042, \mathrm{p}=.003$, Cramer's V $=0.367)$. Thus, as predicted in $\mathrm{H} 1$, when price information was known, laypeople were significantly more likely than professionals to choose the faulty low-priced bid as the winner.

\section{Discussion and introduction to Experiment 2: The effect of revealing price on qualifying problematic bids}

Experiments 1a and 1b simulated decisions in two-stage and one-stage competitive bidding procedures respectively. The procedures reflected those commonly used in real bidding procedures. As expected, professionals were better than laypeople in discriminating between questionable and faulty bids, indicating that professionals are indeed more knowledgeable than laypeople. Importantly, however, the fact that without receiving price information (Experiment 1a), laypeople disqualified faulty bids at similar rates as professionals, suggests that both laypeople and professionals were sufficiently knowledgeable to detect the fault.

Moreover, the fact that laypeople were more likely than experts to approve faulty bids in a one-stage Competitive Bidding, when bids were evaluated with price (Experiment 1b), but not in a two-stage Competitive Bidding, when bids were evaluated without price (Experiment 1a), is in line with the notion that laypeople were more susceptible than experts 
to the Lower Bid Bias. That is, compared to experts, price information had a greater impact on the decisions of laypeople, increasing their tendency to qualify faulty bids.

Whereas the two procedures we employed followed the typical way in which such procedures are implemented in the field, the two procedures differ from one another on two critical aspects. First, the two-stage Competitive Bidding procedure, requires bid evaluators to consider additional information (i.e., price) whereas the one-stage procedure does not. Second the tasks themselves are essentially different: in the two-stage procedure evaluators qualify (i.e., select) several bids that pass on to the final stage, whereas in the one-stage procedure evaluators select and choose only one bid that wins the tender. In laboratory settings we are able to disentangle the two differences by implementing a qualifying task with price information and comparing it to a typical qualifying task without price information. Such a comparison will enable to better assess the role of price information per se. This was the goal of Experiment 2.

\section{Method}

Eighty-two undergraduate students (mean age 25.16, S.D = 2.80, 39 women), and 73 members of bidding committees from a large Israeli Government Company undertaking a mid-career training course participated in the experiment. The participants were asked to consider nine bids in an ostensibly official Competitive Bidding for the acquisition of six electric generators. We employed a between-subjects design. Participants received the bids either with or without seeing their prices and their task was to select those bids that qualified to pass on to the next stage of the Competitive Bidding process. The task was carried out individually.

As in Experiment 1, the bids' details and the competitive bidding prerequisites were presented in a tabular format on a sheet of paper (see Appendix). We included two 
problematic bids. Bid D was questionable since it was not clear whether the bidder had the required work experience. Bid F was faulty as the bidder lacked the mandatory ISO certificate. As in Experiment 1, the problematic bids were also the lowest priced. The faulty bid - Bid F - was the cheapest (\$20.750 million) and the questionable bid - Bid D - was the second cheapest ( $\$ 20.875$ million).

\section{Results}

Figure 3 presents professionals' and laypeople's percentages of qualifying decisions for the problematic bids, with and without knowledge regarding the bids' prices. When assessing the effect of price information on each of the two participant groups, we find that laypeople were affected by price information, professionals were not. The proportions of laypeople that qualified the problematic Bids - Bid D (22\%) and Bid F (12\%) - were significantly lower when prices were sealed than when revealed $(46 \%$ and $34 \%$ for Bid D, and Bid F respectively, $\chi^{2}(1)=5.423, p=.020$, Cramer's $V=0.187$ for bid $\mathrm{D}$ and $\chi^{2}(1)=$ $5.549, p=.018$, Cramer's $\mathrm{V}=0.189$ for bid F). In contrast, the proportions of professionals that qualified Bid D (21\%) and Bid F (21\%) when prices were sealed were not significantly different from the proportions when price information was revealed (23\% and 18\%for Bid D and Bid F respectively, $\chi^{2}(1)=.066, p=.512$, Cramer's $\mathrm{V}=0.021$ for bid $\mathrm{D}$, and $\chi^{2}(1)=$ $.082, p=.503$, Cramer's V $=0.023$ for bid $\mathrm{F}$ ).

In a complementary analysis comparing professionals to laypeople in each of the price conditions (with and without revealing price), we find that when prices were sealed laypeople and professionals did not differ in their tendency to qualify the bids (Bid D- 22\% vs. $27 \%$ and Bid F $12 \%$ vs. $19 \%$ for laypeople and professionals respectively, $\chi^{2}(1)=.021, p$ $=.886$, Cramer's $\mathrm{V}=0.012$ for bid $\mathrm{D}$ and $\chi^{2}(1)=.974, p=.324$, Cramer's $\mathrm{V}=0.079$ for bid F) . In contrast, when prices were revealed laypeople were significantly more likely to pass on Bid D than professionals ( $46 \%$ vs $23 \% \chi^{2}(1)=4.755, p=.029$, Cramer's V $=0.175$ ). The 
difference was in the same direction and marginally significant for Bid F (34\% vs. $18 \%, \chi^{2}(1)$ $=2.709, p=.100$, Cramer's $\mathrm{V}=0.132$ ).

\section{Discussion and introduction to Experiment 3: Attentional processes underlying the}

\section{Lower Bid Bias}

Results of Experiment 2 replicate the superiority of professionals over laypeople in disqualifying problematic bids and demonstrate that price related information impacts laypeople more than professionals. Specifically, supporting H1, laypeople seem to be more susceptible than professionals to Lower Bid Bias. The former are more likely to approve faulty low priced bids than faulty non-priced bids. This finding supports the notion that the difference in results of Experiment $1 \mathrm{a}$ and $1 \mathrm{~b}$ is due to laypeople's susceptibility to Lower Bid Bias and not to other procedural features.

Together, the results of Experiments 1 and 2 suggest that compared to professionals, laypeople are more likely to qualify faulty bids when their price is low. The experiments further indicate that the tendency is not merely due to laypeople's lack of knowledge. Rather, we suggest that the tendency may be attributed to lay-peoples' automatic heuristic-based decision-making processes - i.e., laypeople use their intuition and go for the cheapest option available to them. We designed Experiments $3 \mathrm{a}$ and $3 \mathrm{~b}$ to explore this possibility using eye tracking methodology. In Experiment 3 a we measure eye movements to test the extent to which the preference for cheap bids is intuitive rather than deliberate. In Experiment $3 b$ we examine the extent to which the preference for cheap bids is robust to different presentation formats. First, in line with prior work on attention allocation and choice (e.g., Fiedler et al., 2013; Glöckner et al., 2012; Halevy \& Chou, 2014), we expect that participants will (H2a) choose and (H2b) look longer at the cheap bid compared to the expensive but higher quality bid. Further, if the preference for cheap bids is intuitive, choosing the cheap bid (compared to 
higher quality bid), should be associated with (H3a) more attention to the cheap bid (H3b), faster decisions and (H3c) fewer gaze transitions between the bids

\section{Experiment 3a}

Participants. Thirty students $\left(M_{\mathrm{age}}=25.13, S D_{\mathrm{age}}=2.31,63.33 \%\right.$ female $)$

participated in the experiment in exchange for 15NIS and a chance to earn an additional bonus of 5NIS contingent upon their performance in a randomly selected trial.

Method. Figure 4 depicts the basic experimental paradigm used in Experiments $3 \mathrm{a}$ and 3b. Participants arrived at the lab individually, provided informed consent, and sat in front of an eye-tracking computer. We used a Tobii T120 eye tracker (Tobii Technology, Danderyd, Sweden; sampling rate $=120 \mathrm{~Hz}$; accuracy $=0.45^{\circ}$ ), with a standard nine-point eye-tracking calibration. Participants sat in a private cubicle, $60 \mathrm{~cm}$ in front of a 24-inch eyetracking computer (maximum resolution of $1280 \times 1024$ pixels).

Next, participants read the instructions explaining that they will take the role of a manager in a company and will have to choose which delivery firm to hire. Participants learned that their company recently posted a tender in a local newspaper, which includes three criteria: (1) price, (2) delivery speed, and (3) minimum weight per parcel. For each criterion lower numbers imply better quality (i.e. lower price, faster delivery, and minimal parcel weight). Participants' task was to make 40 sequential choices between 40 pairs of bids, each presented for 10 seconds on the computer screen. Participants were told that all criteria are equally important (see complete instructions in the appendix).

To enhance the contrast between price and quality, one quality criterion (delivery speed) was held constant across all bids. For half of the pairs there was no dominance - i.e., the two bids were exactly equal in their overall value. Specifically, in these non-dominant pairs, one bid was superior in price (i.e. cheaper) but the other was superior in quality (i.e., lower 
minimal weight that is eligible for shipping). For the other half of the pairs, there was dominance - i.e., one bid was superior to the other bid in both price and quality.

Across both types of pairs (with and without dominance), we manipulated task difficulty by varying the relative difference between the two bids. In the dominance pairs, the degree of dominance (i.e., the relative difference between the bids) varied across the following five ratios: $1: 1.1,1: 1.5,1: 2,1: 2.5,1: 3$. For example, the first column of Table 1 depicts a dominance ratio of 1:2 between the bids with respect to both quality and price. The price of the dominant bid (bid A) is half of the price of the non-dominant bid (1000 NIS vs. 2000 NIS), and the quality of the dominant bid (bid A) is twice as good as the quality of the non-dominant bid (makes deliveries of smaller parcels starting at $70 \mathrm{gr}$ vs. 140gr. per parcel). In the no-dominance pairs, where there is no superior bid, we vary the magnitude of conflict between the two bids i.e., the relative price advantage of the cheaper (yet lower quality) bid versus the relative quality advantage of the more expensive one by similarly varying the price-quality ratio to be $1: 1.1,1: 1.5,1: 2,1: 2.5$, or 1:3. For example, the last column of Table 1 depicts a ratio of 1:2. The price of bid A is half of the price of bid B (1000 NIS vs. 2000 NIS), but the quality of Bid A is half as good as the quality of bid B (makes deliveries of bigger parcels starting at 140gr vs. 70gr. per parcel). Generally, the bigger the ratio, the more intense is the conflict between the cheap and the better quality bids. This design enables to explore the extent to which participants prefer low price to superior quality.

Finally, to control for reading directionality effects, we presented each pair four times, in a randomized order, counterbalancing for (a) location of each bid (right vs. left) and (b) location of price and quality criteria (i.e., top vs. bottom). The complete design was thus a within subject design with 40 repeated trials: 2 (Type of bids: Dominance vs. Nondominance) $\times 5$ (Ratio $1: 1.1$ vs. $1: 1.5$ vs. $1: 2$ vs. $1: 2.5$ vs. $1: 3) \times 2$ (Price position: Top vs. Bottom) $\times 2$ (Bids position: Right vs. Left). 
Dependent measures. Participants' choices between the two bids, response time, and eye movements (fixation duration and gaze transitions) during the decision process served as key dependent variables. Table 2 presents all descriptive information of these variables.

\section{Results}

Choices. As can be seen in Table 2 (third column, forth row), in dominance pairs, where one bid dominated the other, participants made the correct choices in $92.66 \%$ of the trials, indicating that they were attentive and understood the task. Supporting H2a, when none of the bids dominated the other, participants displayed a preference for low price bids. They chose the cheap, but quality inferior bid in $74.33 \%$ of the trials, which is significantly greater than the expected $50 \%$ if participants were choosing a bid at random $(\mathrm{Z}=11.88, p<.001)$.

A 2 (Type of bids: Dominance vs. Non-dominance) $\times 5$ (Ratio 1:1.1 vs. 1: 1.5 vs. 1: 2 vs. 1:2.5 vs. $1: 3) \times 2$ (Price position: Top vs. Bottom) generalized linear mixed model predicting the likelihood of choosing the cheap bid revealed no main effect for Ratio, $p=$ .145 or Price position, $p=.518$. Further, the Ratio $\times$ Type of bids, Price position $\times$ Type of bids, and Ratio $\times$ Type of bids $\times$ Price position interactions were not significant, $p>.389$. The main effect for Type of bid was significant, revealing that participants chose the cheap bid more often in the Dominance, compared to Non-dominance pairs of bids, $p<.001$. Because participants' decisions were not influenced by the ratio between the bids nor by the relative position of the price compared to the quality information, in all remaining analyses we collapsed across these factors.

Process. Our next analyses aim to gain further insight into the type of information participants attend to when they choose between quality and price. Specifically, we test hypotheses $\mathrm{H} 2 \mathrm{~b}$ and $\mathrm{H} 3$. Because our main focus is on the decision participants make when quality and price are in conflict, in our eye tracking analyses we focus on trials in which such 
conflict exist, namely on the non-dominant trials. To analyze participants' eye movements we defined four non-overlapping areas of interest (AOI) around the price and weight criteria (see Figure 5).

Fixation durations. We conducted a 2 (AOI of Criteria: price vs. quality) $\times 2$ (AOI of bid type: cheap vs. expensive) $\times 2$ (Participants' choice: cheap bid vs. quality bid) general linear mixed model predicting fixation duration on the relevant AOI. The analysis revealed a main effect of the type of bid. In line with $\mathrm{H} 2 \mathrm{~b}$, participants looked at the cheap bid longer (total duration: $M=1318.36 \mathrm{~ms}, S D=1000.01 \mathrm{~ms})$ than at the expensive bid $(M=1128.20 \mathrm{~ms}$, $S D=880.29 \mathrm{~ms}), F(1,2012)=6.99, p=.008, b=-0.279,95 \% \mathrm{CI}=[-0.409,-0.147]$. This effect was qualified by an AOI of bid $\times$ choice interaction, $F(1,2012)=11.40, p=.001, b=$ $0.314,95 \% \mathrm{CI}=[0.061,0.568]$. Specifically, in-line with hypothesis H3a, participants who chose the cheap bid, exhibited longer fixations on the cheap bid $(M=1376.32 \mathrm{~ms}, S D=$ $1062.90 \mathrm{~ms})$ than on the higher quality bid $(M=1105.35 \mathrm{~ms}, S D=934.47 \mathrm{~ms}), F(1,2012)=$ 33.53, $t(2012)=5.79, p<.001, b=0.275,95 \%$ CI $[0.182,0.368]$. In contrast, participants who chose the higher quality bid, exhibited the same fixation durations on the cheap $(M=$ $1159.41 \mathrm{~ms}, S D=783.14 \mathrm{~ms})$ and high quality bids $(M=1188.90 \mathrm{~ms}, S D=714.73 \mathrm{~ms}), F(1$, $2012)=0.18, p=.667, t(2012)=0.43, b=0.034,95 \%$ CI $[-0.119,0.186]$.

Response time. According to hypothesis H3b choosing the cheap bid will take less time than choosing the higher quality bid. Because response time was not normally distributed (skewness of $5.554[S E=.100]$ and kurtosis of $42.841[S E=.199]$ ), we log transformed the data (skewness of $.859[S E=.100]$ and kurtosis of $1.041[S E=.199]$ after transformation). A generalized linear mixed model with participants' choices (cheap vs. expensive bid) as the independent variable predicting response time revealed a main effect for choosing the cheap bid. In line with H3b, participants who chose the cheap bid (i.e., exhibited preference for low price over high quality bids) responded faster $(M=6583.51 \mathrm{~ms}$, 
$S D=736.87 \mathrm{~ms})$ than participants who chose the higher quality bid $(M=6814.71 \mathrm{~ms}, S D=$ 945.90ms), $F(1,598)=14.39, p<.001, b=0.280,95 \%$ CI $[0.280,0.425]$. This finding suggests that choosing a cheap bid is a quicker, and more intuitive decision than choosing a higher quality bid.

Gaze transitions. Horizontal gaze transitions are the number of times participants switched gazing from one bid to the other. We associate horizontal transitions with the number of comparisons participants make between the bids and use them as a proxy of deliberation. To estimate the extent of deliberation, we calculated the number of horizontal gaze transitions participants made in each trial. The number of switches ranged between 0 and $15(M=5.85, S D=3.22)$. According to hypothesis $\mathrm{H} 3 \mathrm{c}$ we expect participants who choose the cheap (vs. better quality) bid to make fewer gaze transitions between bids, that is, to deliberate less about their decision. A generalized linear mixed model predicting the number of horizontal transitions as a function of choosing the cheap bid (yes vs. no) revealed that on trials in which participants preferred the cheaper bid they made fewer horizontal transitions $(M=5.65, S D=3.18)$ compared to trials in which they chose the higher quality $\operatorname{bid}(M=6.40, S D=3.27), F(1,546)=10.37, p=.001, b=0.805,95 \%$ CI $[0.314,1.296]$. This finding is in line with $\mathrm{H} 3 \mathrm{c}$ and indicates that choosing a low-priced bid is associated with less deliberation than choosing a high-quality bid.

\section{Discussion and introduction to Experiment 3b}

Experiment 3 a examined the underlying process leading to preferring the cheap over the higher quality bid. In line with hypotheses $\mathrm{H} 2 \mathrm{a}$ and $\mathrm{H} 2 \mathrm{~b}$, we found that participants chose more and attended more to the cheap bid than to the better quality bid. In line with hypotheses $\mathrm{H} 3 \mathrm{a}-\mathrm{H} 3 \mathrm{c}$ we found that choosing the cheap bid was associated with increased attention (i.e., longer fixation durations)to the cheap bid, shorter response time and fewer 
between bid comparisons (i.e., gaze transitions). Taken together, the results of Experiment 3a suggest that choosing a qualitatively superior bid takes longer and requires more deliberation than choosing a low priced bid. People seem to deliberate more when choosing quality over (cheap) price.

Experiment 3b has two goals: First, to replicate the findings of Experiment 3a. Second, to examine whether presentation format can shift participants' information processing style from a non-deliberative to a more deliberative one. That is, whether presenting the bids in a certain way can push people to make more between-bid comparisons, and increase their likelihood of choosing the higher quality bid. Indeed, differences in presentation format have been found to impact the preferred decision strategy and consequently actual choices (Bettman \& Kakkar, 1977; Erev et al., 2007; Newell \& Simon, 1972; Russo \& Dosher, 1983). Here we explored whether varying the bids' presentation format by introducing horizontal frames around each criterion (across the two bids) can lead participants to engage in more bid comparisons - i.e., a more deliberative process. The idea is that horizontal frames may cue participants to compare across bids, rather than across criteria (i.e., within bids) by drawing attention to differences between, instead of within bids. Specifically, in Experiment $3 \mathrm{~b}$ we test the effect of horizontal vs. vertical vs. no frames, see Figure 6.

Design. Experiment $3 \mathrm{~b}$ employed the same design as Experiment $3 \mathrm{a}$ with two modifications. First, we focused only 3 ratios (1:1.1, 1:1.2, 1:1.3). Second, we presented each pair of bids three times with horizontal, vertical, or no frames (see Figure 6). If horizontal frames cue participants to compare across bids, rather than across criteria (i.e., within bids), we should find more horizontal gaze transitions and longer response times in the horizontal frame condition compared to the vertical frame and no frame conditions. Such patterns may in turn attenuate the Lower Bid Bias reflected in participants' choices. 
Participants. Thirty-one students $\left(M_{\mathrm{age}}=25.29, S D_{\mathrm{age}}=2.28,48.38 \%\right.$ female $)$ participated in the experiment in exchange for 20NIS and a chance to earn an additional bonus of 5NIS contingent upon their performance in a randomly selected trial.

The experiment employed a within subject design with 72 repeated trials: 3 (Presentation formats: Horizontal frames vs. Vertical frames vs. No frames) $\times 2$ (Type of bids: Dominance vs. No-dominance) $\times 3$ (Ratio 1:1.1 vs. 1:1.2 vs. 1:1.3) $\times 2$ (Price position: Top vs. Bottom) $\times 2$ (Bids position: Right vs. Left). We varied the ratio, as well as the price position and bids position to create variation. However, because we did not have any hypotheses concerning these factors and because we did not find any meaningful interactions in neither Experiment 3a or 3b, we analyze the data collapsing across these factors.

\section{Results}

Choices. As can be seen in the Table 3, in dominance pairs, where one bid dominated the other, participants made the correct choices in $95.34 \%$ of the trials, indicating that they were attentive and understood the task. Replicating the result of Experiment 2, and lending further support to hypothesis $\mathrm{H} 2 \mathrm{a}$, when there was no dominance, participants chose the cheap, but quality inferior bid in $73.02 \%$ of the trials, which is significantly greater than the expected $50 \%$ if participants were choosing a bid at random $(\mathrm{Z}=15.35, p<.001)$.

To test the effect of presentation format on participants' choices, we conducted a generalized linear mixed model with Presentation format (No frame vs. Vertical frame vs. Horizontal frame) predicting the likelihood to choose the cheap, but lower quality bid. The analysis did not reveal a significant effect of presentation format on participant's choices $(F(2,1113)=.424, p=.654)$, and thus does not provide support for the idea that horizontal frames modify participants' choices. 
Process. Our next analyses aim to gain further insight into the effect of presentation format on processing style and to corroborate the findings obtained in Experiment 3a. As in Experiment 3a, choosing the expensive bid in dominant trials is an error, and is indeed highly uncommon (consists of only $4.66 \%$ of choices). Consequently, we continued to focus on nondominant trials only. To analyze participants' gazes we defined four non-overlapping areas of interest around the price and weight criteria, but did not include the fixed criterion (delivery time) in any of the analyses (see Figure 4).

Fixation durations. We conducted a 2 (AOI of criteria: price vs. quality) $\times 2$ (AOI of bid type: cheap vs. expensive $) \times 2$ (Participants' choice: cheap bid vs. quality bid $) \times 3$ (Presentation formats: Horizontal frames vs. Vertical frames vs. No frames) generalized linear mixed model predicting fixation duration on the relevant AOI. The analysis revealed a main effect of the type of bid. Replicating the results obtained in Experiment 3a and in line with $\mathrm{H} 2 \mathrm{~b}$, participants looked at the cheap bid longer (total duration: $M=1306.01 \mathrm{~ms}, S D=$ $938.56 \mathrm{~ms})$ than at the better quality bid $(M=1085.99 \mathrm{~ms}, S D=785.45 \mathrm{~ms}), F(1,4440)=$ $12.61, p<.001, b=-0.338,95 \% \mathrm{CI}=[-0.469,-0.207]$. This effect was qualified by an AOI of bid $\times$ choice interaction, $F(1,4440)=105.26, p<.001, b=0.503,95 \% \mathrm{CI}=[0.244$, 0.762]. Specifically, in-line with hypothesis H3a, participants who chose the cheap bid, exhibited longer fixations on the cheap bid $(M=1358.26 \mathrm{~ms}, S D=991.08 \mathrm{~ms})$ than on the better quality bid $(M=992.06 \mathrm{~ms}, S D=736.37 \mathrm{~ms}), F(1,4440)=176.97, p<.001, t(4440)=$ $13.30, b=0.366,95 \%$ CI $[0.312,0.420]$. However, participants who chose the better quality bid, exhibited longer fixations on that bid $(M=1340.33 \mathrm{~ms}, S D=855.68 \mathrm{~ms})$ than on the cheap $\operatorname{bid}(M=1164.55 \mathrm{~ms}, S D=761.72 \mathrm{~ms}), F(1,4440)=15.40, p<.001, t(4440)=3.92, b=$ $0.178,95 \%$ CI [0.089, 0.267].

Further, although there was a main effect for presentation format, $F(2,4440)=4.03, p$ $=.018$, the only significant difference was between the no frame $(M=1240.91 \mathrm{~ms}, S D=$ 
$866.18 \mathrm{~ms})$ and the horizontal frame conditions $(M=1164.43 \mathrm{~ms}, S D=904.05 \mathrm{~ms}), b=$ $0.090, p=.015, t(4440)=2.800,95 \%$ CI $[0.013,0.168]$. There was no difference between the no frame and the vertical frame conditions $(M=1182.67 \mathrm{~ms}, S D=844.41 \mathrm{~ms}), p=.148$, nor between the vertical and horizontal frame conditions, $p=.328$. Additionally, presentation format did not significantly interact with any other variables, all $p \mathrm{~s}>.282$.

Response time. Because response time was not normally distributed (skewness of $6.405[S E=.073]$ and kurtosis of $53.381[S E=.146)$, we log transformed the data, (skewness of $.412[S E=.073]$ and kurtosis of $3.278[S E=.146]$ after the transformation) and conducted a generalized linear mixed model analysis. A generalized linear mixed model with participants' choices (choosing cheap vs. better quality bid) and Presentation format (No frame vs. Vertical frame vs. Horizontal frame) predicting response time revealed a significant effect for choice. In line with Experiment 3a, and with hypothesis H3b participants who chose the cheap bid, responded faster $(M=6532.87 \mathrm{~ms}, S D=845.66 \mathrm{~ms})$ than participants who chose the better quality bid $(M=6778.37 \mathrm{~ms}, S D=951.64 \mathrm{~ms}), F(1$, $1110)=8.14, p=.004, b=0.191,95 \% \mathrm{CI}=[0.009,0.374]$. This finding suggests that choosing a cheap bid is a quicker, more intuitive decision than choosing a better quality bid.

Additionally, there was a main effect of presentation format, $F(2,1110)=3.26, p=$ .039. We found that participants responded somewhat faster in the no frame condition $(M=$ $6719.53 \mathrm{~ms}, S D=928.91 \mathrm{~ms})$ compared to both the horizontal $(M=6536.19 \mathrm{~ms}, S D=$ $861.70 \mathrm{~ms}), b=0.132, p=.075, t(1110)=2.159,95 \%$ CI $[-0.010,0.274]$ and vertical frame conditions $(M=6541.55 \mathrm{~ms}, S D=842.53 \mathrm{~ms}), b=0.139, p=.075, t(1110)=2.249,95 \%$ CI $[-$ $0.009,0.287]$. There was no difference between the horizontal and vertical frame conditions, $p=.914$. Thus providing no support for the prediction that horizontal frames will lead to shorter response times. The interaction between presentation format and participants' choices was also not significant, $F(2,1110)=1.72, p=.180$. 
Gaze transitions. Next, as in Experiment 3a we counted the number of horizontal gaze transitions (i.e. the number of times participants switched their gaze from one bid to the other). We associate horizontal transitions with the number of comparisons participants made between the bids and use them as a proxy of deliberation. The number of switches ranged between 0 and $19(M=6.90, S D=3.15)$. We conducted a generalized linear mixed model predicting the number of horizontal transitions from the Presentation format (No frame vs. Vertical frame vs. Horizontal frame) and participants' choices (choosing the cheap bid vs. higher quality bid). Replicating Experiment 3a, and in line with hypothesis $\mathrm{H} 3 \mathrm{c}$, results revealed that participants who preferred the cheaper bid made fewer horizontal transitions $(M=6.66, S D=3.02)$ than participants who preferred the quality-wise superior bid $(M=$ $7.56, S D=3.41), F(1,1077)=8.56, p=.003, b=0.689,95 \%$ CI $[0.082,1.295]$. The effects of presentation format and the interaction between presentation format and choice were not significant, $(F(1,1077)=2.00, p=.135 ; F(1,1077)=.24, p=.784)$, respectively. Taken together, these findings suggest that changing the presentation format, and specifically using horizontal frames, did not shift participants' information processing to a more deliberative processing style.

\section{Discussion and introduction to Experiment 4: The role of process accountability}

Experiment $3 \mathrm{~b}$ aimed to replicate the findings regarding the underlying process of Experiment $3 \mathrm{a}$ and further examine the extent to which the bids' presentation format can shift participants processing style from a non-deliberative to a deliberative processing style, and thereby impact preferences. Results indeed replicated the findings of Experiment 3a, and show that choosing the cheap over higher quality bid is a rather intuitive response.

Specifically, participants attend more to cheap over higher quality bids and chose them faster. Further, participants make fewer comparisons between the bids when they chose the cheap 
over the better quality bid. We found no evidence, however, that changing the presentation format, affected participants' processing style nor behavior.

Another way to potentially get people to adopt a relatively more deliberative processing style is by instituting process accountability procedures (Lerner \& Tetlock, 1999; Tetlock, 1992). In Experiment 4 we aim to examine the role of process accountability in mitigating the lower bid bias. As noted in the Introduction, previous research on accountability suggests that a request to explain one's choice reduces cognitive biases because it facilitates a more systematic reason-based and thorough processing of information (e.g., De Dreu et al., 2000; De Dreu et al., 2000; Kirby \& Davis, 1998; Lerner \& Tetlock, 1999; Tetlock, 1992). Therefore, if the difference between professionals and laypeople does indeed stem from the fact that the latter process information in an intuitive, system-1 based manner, then a request to explain their choice might mitigate the gap. Thus as we hypothesized in H4: Laypeople's tendency to qualify low priced faulty bids will be attenuated under a more systematic mode of information processing. Specifically, inducing process accountability will reduce laypeople's tendency to qualify low priced problematic bids.

\section{Method}

Thirty undergraduate students (Mean age $=24.96, \mathrm{SD}=1.60,17$ women) and 35 public procurement officials undertaking a professional training program (mean age $=37.96$, $\mathrm{SD}=10.63,15$ women) participated in Experiment 4 . We employed a variant of the screening task used in Experiment 2. In the current experiment, bids were always screened with price information. The study included two between-subjects accountability conditions (high-accountability vs. low-accountability). Participants in both conditions specified whether each bid should be qualified or disqualified in order to continue to the second stage. To facilitate accountability, we asked participants in the high-accountability condition (but not in the low accountability condition) to explain their decisions. 
All participants were asked to consider a case for the acquisition of wheelchairs for the Ministry of Health for which six bids had been submitted. The Competitive Bidding prerequisites and details of the submitted bids were presented again in a tabular form on a sheet of paper (see Appendix). As in Experiment 2, the Competitive Bidding included two problematic bids: Bid D did not meet the minimal in-market activity criterion and was the cheapest bid; and Bid E did not meet the maximal weight criterion and was the third-cheapest bid. The other four bids complied with the Competitive Bidding prerequisites. The task was carried out individually.

\section{Results}

Figure 7 presents professionals' and laypeople's percentages of qualifying decisions for the problematic bids in the high- and low-accountability conditions. As in previous experiments, there was a clear difference between professionals' and laypeople's choices. Professionals generally qualified the problematic bids less frequently than laypeople. Also, as expected, while the accountability manipulation decreased the tendency of laypeople to choose the faulty bids, it had little effect on professionals. As can be seen, laypeople in the low accountability condition passed on the problematic bids - Bid D and Bid E - in 100\% and $60 \%$ of the cases respectively, while in the high accountability condition they qualified the same bids in only $80 \%$ and $20 \%$ of the cases respectively.

To test the significance of these observations, we compared qualifying proportions in the low- and high-accountability conditions within each group. These comparisons confirmed that the request to explain one's decisions had a greater moderating effect on laypeople than on professionals. Consistent with $\mathrm{H} 4$, the proportions of laypeople qualifying the problematic bids in the high-accountability condition were significantly lower for Bid E (20\% vs. 60\%, for the low vs. high accountability respectively $\chi^{2}(1)=5.00, p=.025$, Cramer's $\mathrm{V}=0.408$ ), and in the same direction, albeit not significant for bid D ( $80 \%$ vs $100 \%$ in the low vs. high 
accountability conditions respectively, $\chi^{2}(1)=2.143, p=.143$, Cramer's V $=0.267$ ). For professionals, on the other hand, where qualifying frequency was already low in the no explanation condition, adding the accountability manipulation did not significantly decrease the tendency to qualify these bids (10\% vs. $5 \%$ for Bid $\mathrm{E}$ in the low and high accountability respectively, $\chi^{2}(1)=.480, p=.580$, Cramer's $\mathrm{V}=0.117$, and $19 \%$ vs $13 \%$ for Bid $\mathrm{D}$, in low and high accountability respectively, $\chi^{2}(1)=.446, p=.489$, Cramer's $\mathrm{V}=0.113$ ).

\section{Discussion}

Results of Experiment 4 demonstrate that the mere request to explain one's decision yielded a significant decrease in laypeople's decisions to qualify problematic bids.

Professionals, on the other hand, were very unlikely to qualify problematic bids even without the requirement to explain, thus leaving little room for further decrease when explanation was required. These results provide further support for the notion that the difference between professionals and laypeople in their susceptibility to the Lower Bid Bias does not merely stem from the fact that the latter group is less knowledgeable and thus unable to discern faults. Rather, it appears that laypeople's tendency to use their intuition makes them focus on cheap prices and subsequently to make suboptimal decisions. When nudged to deliberate, here by increasing their process accountability, they make better choices.

\section{General Discussion}

The research reported here demonstrates the drawbacks of exposing people to complete information. More specifically, we show that exposing bid evaluators to complete information (i.e., including prices) may result in the qualification of faulty low priced bids. Building on several lines within the behavioral decision-making literature - namely, the literature integrating the heuristics and biases approach with naturalistic decision making (NDM) and fuzzy-trace theory - we proposed and found that laypeople are more likely than 
professional procurement officials to qualify faulty bids. We further show that this tendency is not merely driven by lack of knowledge, but rather by the intuitive tendency to favor low priced bids. Finally, we show that a simple instruction increasing people's process accountability substantially improves laypeople's decisions, and reduces their susceptibility to the lower bid bias.

Across a series of experiments, we examined the effect of exposing bid evaluators to price information on the tendency of experts and laypeople to qualify faulty bids. In three experiments, we compared procurement officials to students, and included two problematic bids among the bids to be screened or chosen. Results of Experiments 1a and 1b provided initial indication that price information may affect laypeople more than professionals. Laypeople were as likely as professionals to disqualify a faulty bid when price was concealed, indicating that they were able to identify the fault. However, laypeople were significantly more likely than professionals to choose the faulty bid to be the Competitive Bidding winner when its low price was revealed. Experiment 2 ruled out the possibility that the nature of the task (i.e. qualifying as opposed to choosing), rather than price exposure, drove the different results in Experiments $1 \mathrm{a}$ and $1 \mathrm{~b}$. Experiments $3 \mathrm{a}$ and $3 \mathrm{~b}$ employed eyetracking methodology to uncover the attentional mechanism underlying lay-people's preference for low priced bids. Results revealed that the preference for low priced bids is rather intuitive. Analyzing participants' eye movements revealed that participants who chose the cheap bid compared to the higher quality one made faster decisions and fewer comparisons between the two bids. Results further demonstrate that the preference for cheap bids is robust to presentation format, and that encouraging between-bid comparisons by means of visual cues does not affect the preference for lower priced bids. Finally, in Experiment 4 we examined the role of process accountability (Lerner \& Tetlock, 1999) in attenuating the Lower bid bias. Supporting the process accountability notion, being instructed 
to be accountable significantly reduced laypeople's tendency to qualify faulty low-priced bids.

The findings have theoretical as well as practical implications. First, from a theoretical perspective, the obtained results add to our understanding of the Lower Bid Bias (Dekel \& Schurr, 2014). Whereas prior research only began to document the existence of the phenomenon, the current research demonstrates that the Lower Bid Bias impacts people's choices (i.e., can lead people to qualify and choose faulty bids that have low prices). Furthermore, it identifies the underlying mechanism to the phenomenon namely, intuitive information processing. The finding that experts are less susceptible to the Lower Bid Bias than laypeople, enhances the literature on expert decision-making. Specifically, the finding offers additional support for the notion that experts' make superior decisions in contexts that (a) are sufficiently regular to be predictable (i.e., have highly valid cues), and (b) in which prolonged practice enables to learn these regularities and cues (Kahneman \& Klein, 2009).

An additional contribution pertains to the effect of information on choice. As noted above, statistical models suggest that "information never has a negative value to the decisionmaker. At worst, irrelevant information can be ignored" (Milgrom \& Weber, 1982). In contrast to such premise, our findings demonstrate a particular case where relevant information impedes optimal choice, by showing that exposing laypeople to complete information (quality and price) might lead to suboptimal decisions (i.e. the qualification of a faulty bids). There is a considerable amount of work showing that adding irrelevant information can bias evaluations and decisions. Examples include work related to the anchoring bias, whereby irrelevant values impact subsequent estimations (Feldman, Schurr, \& Teichman, 2012; Northcraft \& Neale, 1987), research showing how irrelevant information such as race, gender, age, religion, and disabilities creates discrimination and impacts hiring and judicial decisions (e.g., Bertrand \& Mullainathan, 2005; Wistrich, Guthrie, \& Rachlinski, 
2005), and research documenting that irrelevant input information about investments of time or effort, impacts outcome evaluations (Chinander \& Schweitzer, 2003). Our findings extend this line of work by demonstrating that highly relevant information (such as price), can also result in biased evaluations and wrong decisions. Price information draws attention and may lead to bad choices.

The present work complements the broader literature on the relationship between price and quality. One of the basic notions about the price-quality relationship is that high prices are associated with superior quality. This is manifested in the well-documented pricequality heuristic, according to which people typically use price as a proxy for quality (Gerstner, 1985; Gneezy, Gneezy, \& Lauga, 2014; Huber \& McCann, 1982; Rao \& Monroe, 1989; Riesz, 1979). Recently, (Gneezy et al., 2014) proposed a reference dependent model, whereby the link between price and quality is mediated by expectations. Specifically, they suggest that high prices set high quality expectations and that meeting these expectations is a critical moderator of the heuristic. Namely, when high priced products do not meet expectations, the price-quality relationship is reversed. Relatedly, the present work, extends this idea by demonstrating that in some circumstances the relation between price and quality may be negative, already at the initial pre-experiencing stage.

From a practical perspective, our findings have several implications. First, organizations that desire to alleviate a potential Lower Bid Bias should employ experienced professionals in their procurement activities and invest in their training. Our results also have implications regarding ways to lessen the bias when employees are less experienced and professional. Specifically, organizations may neutralize the lower bid bias by adopting a twostage evaluation process by which the bid price is submitted along with the other components of the bid, but in a separate sealed envelope that is opened only upon completing the bid evaluation stage. Going beyond the context of procurement, such two-stage mechanisms may 
also reduce bias in other contexts, where there is information that might bias the decisionmaker. Examples include, but are not limited to, judicial or hiring decisions whereby exposing information about gender or race may evince discrimination. Improving laypeople's decisions is important for two reasons. First, organizational constraints often limit the ability to ascertain that employees always deal with and make decisions in their specific areas of expertise. For example, members of bidding committees often include people with limited expertise in procurement. Second, public firms and organizations are often required to employ people who are not experts in the firm's field, and yet are part of the firms' decisionmaking process - one such example is the legal requirement to seat public representatives on boards of directors.

Lastly, our findings regarding the effectiveness of a relatively simple process accountability manipulation in reducing laypeople's LBB, suggest that organizations should consider formally implementing a process accountability requirement as part of their decision-making procedures. One way to implement this idea is to create an organizational climate of accountability by instituting ongoing review process procedures that encourage employees to think about their decisions and justify them before they are finalized. Research shows that such organizational changes may have long-lasting effects (Schurr, Rodensky, \& Erev, 2014). Another way to implement this idea is through targeted interventions. In line with (Fischhoff, 1982; Sellier, Scopelliti, \& Morewedge, 2019) initial attempts to debias decision-makers, and with the recent findings of (Morewedge et al., 2015; Sellier et al., 2019) pertaining to debiasing training, it educating people about the lower bid bias may mitigate the bias and improve judgments.

We conclude with the famous phrase attributed to Benjamin Franklin: "A penny saved is a penny earned". While we agree that saving money is a commendable objective, our results imply that such a focus on saving money can, at times, be expensive. Thus, we 
propose that it is comparably important to be aware of the fact that "a penny saved can result in a two-penny loss." As a safeguard against the latter, we offer several empirically based procedural and structural recommendations - namely, to utilize professional bid evaluators, embed process accountability, and employ a two-stage process. 


\section{References}

Ashton, R. H. (1992). Effects of justification and a mechanical aid on judgment performance. Organizational Behavior and Human Decision Processes, 52(2), 292-306.

Bazerman, M., \& Moore, D. A. (2012). Judgment in managerial decision making.

Bertrand, M., \& Mullainathan, S. (2005). Implicit discrimination. The American Economic Review, 95(2), 94-98.

Bettman, J. R., \& Kakkar, P. (1977). Effects of information presentation format on consumer information acquisition strategies. Journal of Consumer Research, , 233-240.

Brainerd, C. J., \& Reyna, V. F. (1990). Gist is the grist: Fuzzy-trace theory and the new intuitionism. Developmental Review, 10(1), 3-47.

Brtek, M. D., \& Motowidlo, S. J. (2002). Effects of procedure and outcome accountability on interview validity. Journal of Applied Psychology, 87(1), 185.

Chase, W. G., \& Simon, H. A. (1973). The mind's eye in chess.

Chinander, K. R., \& Schweitzer, M. E. (2003). The input bias: The misuse of input information in judgments of outcomes. Organizational Behavior and Human Decision Processes, 91(2), 243-253.

Chua, E. F., Hannula, D. E., \& Ranganath, C. (2012). Distinguishing highly confident accurate and inaccurate memory: Insights about relevant and irrelevant influences on memory confidence. Memory, 20(1), 48-62. 
Chugh, D., Bazerman, M. H., \& Banaji, M. R. (2005). Bounded ethicality as a psychological barrier to recognizing conflicts of interest. Conflicts of Interest: Challenges and Solutions in Business, Law, Medicine, and Public Policy, , 74-95.

Crandall, B., \& Getchell-Reiter, K. (1993). Critical decision method: A technique for eliciting concrete assessment indicators from the intuition of NICU nurses. Advances in Nursing Science, 16(1), 42-51.

De Dreu, C. K., Koole, S. L., \& Steinel, W. (2000). Unfixing the fixed pie: A motivated information-processing approach to integrative negotiation. Journal of Personality and Social Psychology, 79(6), 975.

De Groot, A. (1978). Thought and choice in chess (revised translation of de groot, 1946. The Hague: Mouton Publishers,

DeKay, M. L. (2015). Predecisional information distortion and the self-fulfilling prophecy of early preferences in choice. Current Directions in Psychological Science, 24(5), 405411.

Dekel, O., \& Schurr, A. (2014). Cognitive biases in government Procurement-An experimental study. Review of Law \& Economics, 10(2), 169-200.

Erev, I., Shimonowitch, D., Schurr, A., \& Hertwig, R. (2007). Base rates: How to make the intuitive mind appreciate or neglect them. Intuition in Judgment and Decision Making, Ed.H.Plessner, C.Betsch \& T.Betsch, , 135-148.

Feldman, Y., Schurr, A., \& Teichman, D. (2012). Reference points and contract interpretation: An empirical examination. Manuscript on File with Author, 
Fiedler, S., Glöckner, A., Nicklisch, A., \& Dickert, S. (2013). Social value orientation and information search in social dilemmas: An eye-tracking analysis. Organizational Behavior and Human Decision Processes, 120(2), 272-284.

Fischhoff, B. (1982). Debiasing/kahneman, d., slovic, p. and tversky, a.

Gawande, A. (2002). Education of a knife. Complications: A Surgeon's Notes on an Imperfect Science, , 11-34.

Gerstner, E. (1985). Do higher prices signal higher quality? Journal of Marketing Research, , 209-215.

Gilovich, T., Griffin, D., \& Kahneman, D. (2002). Heuristics and biases: The psychology of intuitive judgment Cambridge University Press.

Glöckner, A., Fiedler, S., Hochman, G., Ayal, S., \& Hilbig, B. (2012). Processing differences between descriptions and experience: A comparative analysis using eye-tracking and physiological measures. Frontiers in Psychology, 3, 173.

Glöckner, A., \& Herbold, A. (2011). An eye-tracking study on information processing in risky decisions: Evidence for compensatory strategies based on automatic processes. Journal of Behavioral Decision Making, 24(1), 71-98.

Gneezy, A., Gneezy, U., \& Lauga, D. O. (2014). A reference-dependent model of the pricequality heuristic. Journal of Marketing Research, 51(2), 153-164.

Groopman, J. E., \& Prichard, M. (2007). How doctors think Springer. 
Halevy, N., \& Chou, E. Y. (2014). How decisions happen: Focal points and blind spots in interdependent decision making. Journal of Personality and Social Psychology, 106(3), 398.

Hochman, G., Glöckner, A., Fiedler, S., \& Ayal, S. (2016). "I can see it in your eyes": Biased processing and increased arousal in dishonest responses. Journal of Behavioral Decision Making, 29(2-3), 322-335.

Horstmann, N., Ahlgrimm, A., \& Glöckner, A. (2009). How distinct are intuition and deliberation? an eye-tracking analysis of instruction-induced decision modes. An EyeTracking Analysis of Instruction-Induced Decision Modes (April 1, 2009).MPI Collective Goods Preprint, (2009/10)

Hristova, E., \& Grinberg, M. (2008). Disjunction effect in prisoner's dilemma: Evidences from an eye-tracking study. Paper presented at the Proceedings of the 30th Annual Conference of the Cognitive Science Society, 1225-1230.

Hsee, C. K., \& Zhang, J. (2004). Distinction bias: Misprediction and mischoice due to joint evaluation. Journal of Personality and Social Psychology, 86(5), 680.

Huber, J., \& McCann, J. (1982). The impact of inferential beliefs on product evaluations. Journal of Marketing Research, , 324-333.

Innocenti, A., Rufa, A., \& Semmoloni, J. (2010). Overconfident behavior in informational cascades: An eye-tracking study. Journal of Neuroscience, Psychology, and Economics, 3(2), 74 .

Just, M. A., \& Carpenter, P. A. (1976). Eye fixations and cognitive processes. Cognitive Psychology, 8(4), 441-480. 
Kahneman, D. (2011). Thinking, fast and slow Macmillan.

Kahneman, D., \& Klein, G. (2009). Conditions for intuitive expertise: A failure to disagree. American Psychologist, 64(6), 515.

Kirby, S. L., \& Davis, M. A. (1998). A study of escalating commitment in principal-agent relationships: Effects of monitoring and personal responsibility. Journal of Applied Psychology, 83(2), 206.

Klein, G. A., Calderwood, R., \& Clinton-Cirocco, A. (1986). Rapid decision making on the fire ground. Paper presented at the Proceedings of the Human Factors and Ergonomics Society Annual Meeting, , 30(6) 576-580.

Krajbich, I., \& Rangel, A. (2011). Multialternative drift-diffusion model predicts the relationship between visual fixations and choice in value-based decisions. Proceedings of the National Academy of Sciences of the United States of America, 108(33), 1385213857. doi:10.1073/pnas.1101328108 [doi]

Lerner, J. S., \& Tetlock, P. E. (1999). Accounting for the effects of accountability. Psychological Bulletin, 125(2), 255.

March, J. G., \& Simon, H. A. (1958). Organizations.

Milgrom, P., \& Weber, R. J. (1982). The value of information in a sealed-bid auction. Journal of Mathematical Economics, 10(1), 105-114.

Morewedge, C. K., \& Kahneman, D. (2010). Associative processes in intuitive judgment. Trends in Cognitive Sciences, 14(10), 435-440. 
Morewedge, C. K., Yoon, H., Scopelliti, I., Symborski, C. W., Korris, J. H., \& Kassam, K. S. (2015). Debiasing decisions: Improved decision making with a single training intervention. Policy Insights from the Behavioral and Brain Sciences, 2(1), 129-140.

Newell, A., \& Simon, H. A. (1972). Human problem solving Prentice-Hall Englewood Cliffs, NJ.

Northcraft, G. B., \& Neale, M. A. (1987). Experts, amateurs, and real estate: An anchoringand-adjustment perspective on property pricing decisions. Organizational Behavior and Human Decision Processes, 39(1), 84-97.

Pittarello, A., Fratescu, M., \& Mathôt, S. (2019). Visual saliency influences ethical blind spots and (dis) honesty. Psychonomic Bulletin \& Review, 26(5), 1719-1728.

Rao, A. R., \& Monroe, K. B. (1989). The effect of price, brand name, and store name on buyers' perceptions of product quality: An integrative review. Journal of Marketing Research, , 351-357.

Reyna, V. F., \& Brainerd, C. J. (1995). Fuzzy-trace theory: An interim synthesis. Learning and Individual Differences, 7(1), 1-75.

Reyna, V. F., \& Lloyd, F. J. (2006). Physician decision making and cardiac risk: Effects of knowledge, risk perception, risk tolerance, and fuzzy processing. Journal of Experimental Psychology: Applied, 12(3), 179.

Reyna, V. F. (2012). A new intuitionism: Meaning, memory, and development in fuzzy-trace theory. Judgment and Decision Making, 7(3), 332-359. 
Reyna, V. F., Chick, C. F., Corbin, J. C., \& Hsia, A. N. (2014). Developmental reversals in risky decision making: Intelligence agents show larger decision biases than college students. Psychological Science, 25(1), 76-84. doi:10.1177/0956797613497022 [doi]

Riesz, P. C. (1979). Price-quality correlations for packaged food products. Journal of Consumer Affairs, 13(2), 236-247.

Russo, J. E. (1978). Eye fixations can save the world: A critical evaluation and a comparison between eye fixations and other information processing methodologies. Advances in Consumer Research, 5(1)

Russo, J. E., \& Dosher, B. A. (1983). Strategies for multiattribute binary choice. Journal of Experimental Psychology: Learning, Memory, and Cognition, 9(4), 676.

Russo, J. E., \& Leclerc, F. (1994). An eye-fixation analysis of choice processes for consumer nondurables. Journal of Consumer Research, , 274-290.

Russo, J. E., \& Rosen, L. D. (1975). An eye fixation analysis of multialternative choice. Memory \& Cognition, 3(3), 267-276.

Schkade, D. A., \& Kahneman, D. (1998). Does living in california make people happy? A focusing illusion in judgments of life satisfaction. Psychological Science, 9(5), 340-346.

Schurr, A., Rodensky, D., \& Erev, I. (2014). The effect of unpleasant experiences on evaluation and behavior. Journal of Economic Behavior \& Organization, 106, 1-9.

Sellier, A., Scopelliti, I., \& Morewedge, C. K. (2019). Debiasing training improves decision making in the field. Psychological Science, 30(9), 1371-1379. 
Siegel-Jacobs, K., \& Yates, J. F. (1996). Effects of procedural and outcome accountability on judgment quality. Organizational Behavior and Human Decision Processes, 65(1), 1-17.

Simon, H. A. (1957). Models of man; social and rational.

Simonson, I., \& Staw, B. M. (1992). Deescalation strategies: A comparison of techniques for reducing commitment to losing courses of action. Journal of Applied Psychology, 77(4), 419.

Sloman, S. A. (1996). The empirical case for two systems of reasoning. Psychological Bulletin, 119(1), 3.

Tetlock, P. E. (1992). The impact of accountability on judgment and choice: Toward a social contingency model. Advances in Experimental Social Psychology, 25(3), 331-376.

Tetlock, P. E., Vieider, F. M., Patil, S. V., \& Grant, A. M. (2013). Accountability and ideology: When left looks right and right looks left. Organizational Behavior and Human Decision Processes, 122(1), 22-35.

Tversky, A., \& Kahneman, D. (1974). Judgment under uncertainty: Heuristics and biases. Science (New York, N.Y.), 185(4157), 1124-1131. doi:185/4157/1124 [pii]

Wang, J., \& Spezio, M.C. camerer (2010). pinocchio's pupil: Using eyetracking and pupil dilation to understand truth-telling and deception in games. American Economic Review, $100,9841007$.

Wilson, T. D., Wheatley, T., Meyers, J. M., Gilbert, D. T., \& Axsom, D. (2000). Focalism: A source of durability bias in affective forecasting. Journal of Personality and Social Psychology, 78(5), 821. 
Wistrich, A. J., Guthrie, C., \& Rachlinski, J. J. (2005). Can judges ignore inadmissible information? the difficulty of deliberately disregarding. University of Pennsylvania Law Review, , 1251-1345.

Zsambok, C. E., \& Klein, G. (2014). Naturalistic decision making Psychology Press. 


\section{Appendix}

\section{Materials used in Experiments 1a and 1b}

The following case is based on a real competitive bidding conducted by the Ministry of Health. Together with the opening of the new medical school in Safed [a city in northern Israel] the Ministry of Health decided to publish an IFB for the building of an advanced pediatric oncology clinic. The clinic was meant to be a part of the hospital in Safed, which did not yet have those facilities, and sick children were therefore required to travel to distant hospitals in order to receive the treatment they required.

[Experiment 1a: The bidders were asked to submit the bid amount in a separate sealed envelope, to be opened after the examination of the other parts of the bids. Upon the completion of this examination (except for the price) you received the following document:]

[Experiment 1b: After the completion of the examination you were asked to determine who should win the IFB, based on the following document:]

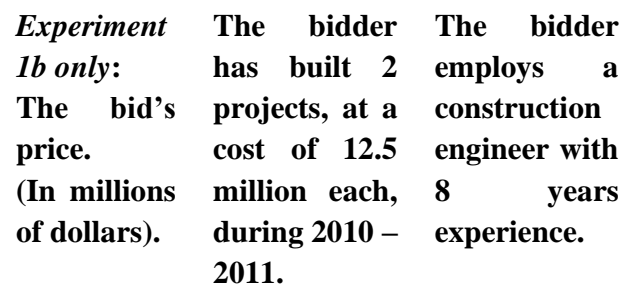

The bidder is
officially
registered as
"unlimited".

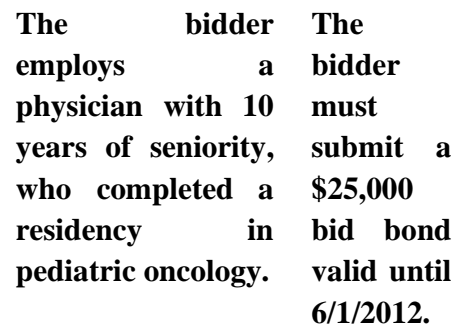

\begin{tabular}{|c|c|c|c|c|c|c|c|}
\hline $\begin{array}{c}\text { Bid } \\
\text { A }\end{array}$ & 17.8 & $\mathrm{~V}$ & See comments & $\mathrm{V}$ & V & $\mathrm{V}$ & $\begin{array}{l}\text { According to the } \\
\text { certification attached, } \\
\text { the engineer has } 6 \\
\text { years and } 8 \text { months of } \\
\text { experience. }\end{array}$ \\
\hline $\begin{array}{c}\text { Bid } \\
\text { B }\end{array}$ & 18.9 & $\mathrm{~V}$ & V & $\mathrm{V}$ & See comments & $\mathrm{V}$ & $\begin{array}{l}\text { Residency in general } \\
\text { oncology (completed } \\
\text { in 1993), because there } \\
\text { were no pediatric } \\
\text { oncology residencies } \\
\text { in Israel at that time. } \\
\text { Since then has worked } \\
\text { as a pediatric } \\
\text { oncologist in a } \\
\text { hospital. }\end{array}$ \\
\hline $\begin{array}{c}\text { Bid } \\
\text { C }\end{array}$ & 20.3 & V & V & $\mathrm{V}$ & V & $\mathrm{V}$ & $\begin{array}{l}\text { The bid complies with } \\
\text { the requirements. }\end{array}$ \\
\hline $\begin{array}{c}\text { Bid } \\
\text { D }\end{array}$ & 20.8 & V & V & V & V & $\mathrm{V}$ & $\begin{array}{l}\text { The bid complies with } \\
\text { the requirements. }\end{array}$ \\
\hline
\end{tabular}

[Experiment 1a: Mark the bids that will proceed to the next stage (the opening of the price envelopes):]

[Experiment 1b: Mark the winning bid:]
Bid A
Bid B
Bid C
Bid D 


\section{Materials used in Experiment 2}

\section{Invitation for Bids No. A041024211 for the supply of 45 megawatt Generators}

The company's contracting committee wants to share with you a dilemma laid on its table these days. Read the following and mark/indicate what would be your decision as a contracting committee member. Due to expected manufacturing deficiency/shortage in electric supply in the coming summer the company has published an international Request for Proposals (RFP) for the acquisition of 6 Generators each of them 45 megawatt load/power. The preliminary assessment of the transaction cost is 3.5 million dollars for each generator, a total of 21 million dollars.

\begin{tabular}{|c|c|c|c|c|c|c|}
\hline & $\begin{array}{c}\text { Price } \\
\text { (Price information } \\
\text { was presented only } \\
\text { to participants in } \\
\text { the "With price" } \\
\text { condition) }\end{array}$ & $\begin{array}{c}\text { ISO 9001, } 2010 \\
\text { edition }\end{array}$ & $\begin{array}{c}\text { The bidder has a } 5 \\
\text { years experience in } \\
\text { the field }\end{array}$ & $\begin{array}{c}\text { Five years } \\
\text { guarantee for } \\
\text { the product }\end{array}$ & $\begin{array}{c}\text { Obligation to } \\
\text { supply at least } 2 \\
\text { generators } \\
\text { within } 60 \text { days } \\
\text { from the notice } \\
\text { of winning. } \\
\end{array}$ & comments \\
\hline Bid A & $23,000,000 \$$ & $\mathrm{~V}$ & $\mathrm{~V}$ & $\mathrm{~V}$ & $\mathrm{~V}$ & $\begin{array}{l}\text { The bid complies with } \\
\text { the requirements. }\end{array}$ \\
\hline Bid B & $21,550,000 \$$ & V & V & V & V & $\begin{array}{l}\text { The bid complies with } \\
\text { the requirements. }\end{array}$ \\
\hline Bid C & $25,250,000 \$$ & V & V & $\begin{array}{c}\mathrm{V} \\
\text { (See comments) }\end{array}$ & V & $\begin{array}{l}\text { The bid complies with } \\
\text { the requirements. The } \\
\text { bidder has } 37 \text { years of } \\
\text { experience. }\end{array}$ \\
\hline Bid D & $20,875,000 \$$ & V & V & (See comments) & V & $\begin{array}{l}\text { The bidder has } 42 \\
\text { years of experience in } \\
\text { manufacturing } \\
\text { turbines, but only } 4.5 \\
\text { years of experience in } \\
\text { manufacturing } \\
\text { generators. }\end{array}$ \\
\hline Bid E & $24,750,000 \$$ & V & V & V & V & $\begin{array}{c}\text { The bid complies with } \\
\text { the requirements. }\end{array}$ \\
\hline Bid F & $20,750,000 \$$ & (See comments) & V & V & V & $\begin{array}{c}\text { The bidder does not } \\
\text { have ISO certificate, } \\
\text { but declared that he has } \\
\text { finished the } \\
\text { certification process } \\
\text { and expects to get the } \\
\text { certification in a week. }\end{array}$ \\
\hline Bid G & $23,875,000 \$$ & V & V & V & V & $\begin{array}{c}\text { The bid complies with } \\
\text { the requirements. }\end{array}$ \\
\hline Bid H & $21,675,000 \$$ & V & $\begin{array}{c}\mathrm{V} \\
\text { (See comments) }\end{array}$ & V & V & $\begin{array}{c}\text { The bid complies with } \\
\text { the requirements. The } \\
\text { bidder gave } 10 \text { years } \\
\text { guarantee. }\end{array}$ \\
\hline Bid I & $23,200,000 \$$ & V & V & V & V & $\begin{array}{c}\text { The bid complies with } \\
\text { the requirements. }\end{array}$ \\
\hline
\end{tabular}

Please mark the bids that are qualified to pass on to the next stage:

\begin{tabular}{|l|l|l|l|l|l|l|l|l|}
\hline Bid A & Bid B & Bid C & Bid D & Bid E & Bid F & Bid G & Bid H & Bid I \\
\hline
\end{tabular}




\section{Materials used in Experiment 3a and 3b}

Thank you for taking part in the experiment.

The goal of the study is to evaluate the way exposure to information affects people decision making. In this study you are a manager of a successful internet company that sells goods worldwide.

Recently, your business is expending and you have decided to hire a delivery company. In order to do so, you posted a tender that calls delivery companies to offer you their services.

The tender includes three criteria (1) price, (2) delivery speed, and (3) minimum weight per parcel. All criteria are equally important to you.

Different companies are now offering their services to you. In order to make it easier to you, we will present you with 40 (Exp. 3a) / 72 (Exp. 3b) pairs of offers and each time you will have to choose the winning offer.

Each pair will be presented for 10 seconds on the screen, after that you will be asked to choose the best offer.

Note that for each criterion, the lower the number, the better the offer. That is, it is better to pay a low price over an expensive price; it is better to receive the delivery faster than slower; and it is better to have a lower minimum weight per parcel. Nonetheless, the decision what offer to choose is up to you. 


\section{Materials used in Experiment 4}

The following case is based on a real tender, conducted by the Ministry of Health. The Ministry of Health has published a request for proposals (RFP) for the acquisition of 3000 wheelchairs (see the table below). The preliminary assessment of the transaction cost is NIS 2,100 per wheel chair, a total of NIS 6.3 million. Please indicate for each bid whether it does or does not qualify to pass on to the next stage [participants in the high accountability condition were also asked to write a short, one sentence long, explanation for their decision]

\begin{tabular}{|c|c|c|c|c|c|c|}
\hline & $\begin{array}{l}\text { Prior estimate } \\
2100 \text { NIS } \\
\text { Price }\end{array}$ & $\begin{array}{c}\text { ISO 9001, } \\
2010 \text { edition }\end{array}$ & $\begin{array}{c}10 \text { years } \\
\text { experience } \\
\text { manufacturing } \\
\text { wheelchairs } \\
\end{array}$ & $\begin{array}{c}2 \text { years } \\
\text { guarantee }\end{array}$ & $\begin{array}{l}\text { Weight does not } \\
\text { exceed } 10 \mathrm{Kg} \text {. }\end{array}$ & Comments \\
\hline Bid A & 2150 & $\mathrm{~V}$ & $\mathrm{~V}$ & $\mathrm{~V}$ & $\bar{V}$ & $\begin{array}{c}\text { The bid } \\
\text { complies with } \\
\text { the } \\
\text { requirements. }\end{array}$ \\
\hline Bid B & 2350 & V & V & V & $\mathrm{V}$ & $\begin{array}{l}\text { The bid } \\
\text { complies with } \\
\text { the } \\
\text { requirements. } \\
\text { The bidder has } \\
25 \text { years of } \\
\text { experience }\end{array}$ \\
\hline Bid C & 2150 & V & V & V & V & $\begin{array}{l}\text { The bid } \\
\text { complies with } \\
\text { the } \\
\text { requirements. }\end{array}$ \\
\hline Bid D & 1920 & V & See Comment & $\mathrm{V}$ & $\mathrm{V}$ & $\begin{array}{c}\text { The company } \\
\text { was established } \\
9 \text { years and } 9 \\
\text { months ago. } \\
\text { The CEO has } 18 \\
\text { years of } \\
\text { experience in } \\
\text { the field. }\end{array}$ \\
\hline Bid E & 2100 & V & V & V & See Comment & $\begin{array}{c}\text { The wheelchair } \\
\text { weighs } 10 \mathrm{KG} \\
\text { and } 75 \text { gr. } 3 \\
\text { years guarantee. }\end{array}$ \\
\hline Bid F & 2000 & V & V & V & $\mathrm{V}$ & $\begin{array}{l}\text { The bid } \\
\text { complies with } \\
\text { the } \\
\text { requirements. }\end{array}$ \\
\hline
\end{tabular}


Table 1. Example of Bids used in Experiment 3a and 3b

\begin{tabular}{|c|c|c|c|}
\hline \multicolumn{2}{|c|}{ Dominant price-quality 2:1 ratio } & \multicolumn{2}{c|}{ Non-dominant price-quality ratio 2:1 } \\
\hline BID A & BID B & BID A & BID B \\
\hline 1000 NIS per month & 2000 NIS per month & 1000 NIS per month & 2000 NIS per month \\
\hline 70 gr per parcel & 70 gr per parcel & 70 gr per parcel & 70 gr per parcel \\
\hline 1 day delivery & 2 days delivery & 2 days delivery & 1 day delivery \\
\hline
\end{tabular}

Note to Table 1. Table 1 depicts two decision problems. The first problem on the left panel does not carry a conflict: Bidder A is cheaper than bidder B (100NIS vs. 200 NIS) and offers a faster delivery service than Bidder B (1-day vs. 2-day delivery service). The right panel depict a decision problem that carries a conflict. Bidder A is cheaper than bidder B (100NIS vs. 200 NIS) but, on the other hand, Bidder A offers a 2- day delivery service whereas Bidder B offers a faster 1-day delivery service. In Experiments 3a and $3 \mathrm{~b}$ participants chose between the bids while eye movements gaze durations and reaction times were being recorded. 
Table 2. All M's (SD's) for the dependent variables in Experiment 3a.

\begin{tabular}{|c|c|c|c|c|c|c|c|c|}
\hline & & \multirow{3}{*}{$\begin{array}{l}\text { Choice } \\
(\%)\end{array}$} & \multirow{3}{*}{$\begin{array}{l}\text { Response time } \\
(\mathrm{ms})\end{array}$} & \multicolumn{4}{|c|}{ Fixation durations (ms) } & \multirow{3}{*}{$\begin{array}{c}\text { Between bid } \\
\text { comparisons } \\
\text { (N horizonta } \\
\text { transitions) }\end{array}$} \\
\hline & & & & \multicolumn{2}{|c|}{ AOI - price } & \multicolumn{2}{|c|}{ AOI- quality } & \\
\hline & & & & $\begin{array}{l}\text { Cheap, } \\
\text { quality } \\
\text { inferior bid }\end{array}$ & $\begin{array}{c}\text { Expensive, } \\
\text { quality } \\
\text { superior bid }\end{array}$ & $\begin{array}{l}\text { Cheap, quality } \\
\text { inferior bid }\end{array}$ & $\begin{array}{l}\text { Expensive, } \\
\text { quality superior } \\
\text { bid }\end{array}$ & \\
\hline \multirow[t]{2}{*}{$\begin{array}{l}\text { Dominance } \\
\text { pairs }\end{array}$} & Chose cheap bid & $92.66 \%$ & $\begin{array}{l}6353.31 \\
(622.40)\end{array}$ & $\begin{array}{l}1388.79 \\
(1154.63)\end{array}$ & $\begin{array}{c}939.04 \\
(800.85)\end{array}$ & $\begin{array}{l}1312.01 \\
(1189.00)\end{array}$ & $\begin{array}{c}932.68 \\
(894.10)\end{array}$ & $\begin{array}{l}5.16 \\
(2.84)\end{array}$ \\
\hline & $\begin{array}{l}\text { Chose expensive } \\
\text { bid }\end{array}$ & $7.34 \%$ & $\begin{array}{l}7141.44 \\
(853.22)\end{array}$ & $\begin{array}{c}944.73 \\
(915.40)\end{array}$ & $\begin{array}{c}1213.61 \\
(1235.67)\end{array}$ & $\begin{array}{l}914.28 \\
(774.08)\end{array}$ & $\begin{array}{c}1426.77 \\
(1483.20)\end{array}$ & $\begin{array}{l}4.17 \\
(2.92)\end{array}$ \\
\hline \multirow[t]{2}{*}{$\begin{array}{l}\text { No- } \\
\text { dominance } \\
\text { pairs }\end{array}$} & Chose cheap bid & $74.33 \%$ & $\begin{array}{l}6583.51 \\
(736.87)\end{array}$ & $\begin{array}{l}1395.16 \\
(1029.54)\end{array}$ & $\begin{array}{l}1122.21 \\
(981.21)\end{array}$ & $\begin{array}{c}1357.98 \\
(1098.73)\end{array}$ & $\begin{array}{l}1088.31 \\
(885.75)\end{array}$ & $\begin{array}{c}5.65 \\
(3.18)\end{array}$ \\
\hline & $\begin{array}{l}\text { Chose expensive } \\
\text { bid }\end{array}$ & $25.67 \%$ & $\begin{array}{l}6814.12 \\
(945.90)\end{array}$ & $\begin{array}{l}1227.35 \\
(884.32)\end{array}$ & $\begin{array}{l}1254.34 \\
(739.13)\end{array}$ & $\begin{array}{l}1091.47 \\
(663.20)\end{array}$ & $\begin{array}{l}1122.50 \\
(685.41)\end{array}$ & $\begin{array}{c}6.40 \\
(3.26)\end{array}$ \\
\hline
\end{tabular}


Table 3. All M's (SD's) for the dependent variables in Experiment $3 \mathrm{~b}$.

\begin{tabular}{|c|c|c|c|c|c|c|c|c|}
\hline & & \multirow{3}{*}{$\begin{array}{c}\text { Choice } \\
(\%)\end{array}$} & \multirow{3}{*}{$\begin{array}{l}\text { Response time } \\
(\mathrm{ms})\end{array}$} & \multicolumn{4}{|c|}{ Fixation durations (ms) } & \multirow{3}{*}{$\begin{array}{c}\text { Between bid } \\
\text { comparisons } \\
\text { ( } \mathrm{N} \text { horizontal } \\
\text { transitions) }\end{array}$} \\
\hline & & & & \multicolumn{2}{|c|}{ AOI - price } & \multicolumn{2}{|c|}{ AOI- quality } & \\
\hline & & & & $\begin{array}{l}\text { Cheap, quality } \\
\text { inferior bid }\end{array}$ & $\begin{array}{l}\text { Expensive, } \\
\text { quality } \\
\text { superior bid }\end{array}$ & $\begin{array}{l}\text { Cheap, quality } \\
\text { inferior bid }\end{array}$ & $\begin{array}{l}\text { Expensive, quality } \\
\text { superior bid }\end{array}$ & \\
\hline \multirow[t]{2}{*}{$\begin{array}{l}\text { Dominance } \\
\text { pairs }\end{array}$} & Chose cheap bid & $95.34 \%$ & $\begin{array}{l}6313.19 \\
(647.16)\end{array}$ & $\begin{array}{c}1332.43 \\
(1074.76)\end{array}$ & $\begin{array}{c}904.06 \\
(736.92)\end{array}$ & $\begin{array}{l}1142.80 \\
(962.01)\end{array}$ & $\begin{array}{c}774.66 \\
(677.20)\end{array}$ & $\begin{array}{c}5.74 \\
(2.79)\end{array}$ \\
\hline & $\begin{array}{l}\text { Chose expensive } \\
\text { bid }\end{array}$ & $4.66 \%$ & $\begin{array}{c}6829.57 \\
(1097.31)\end{array}$ & $\begin{array}{l}1106.73 \\
(683.68)\end{array}$ & $\begin{array}{l}1491.53 \\
(863.10)\end{array}$ & $\begin{array}{l}1152.50 \\
(819.59)\end{array}$ & $\begin{array}{l}1284.42 \\
(669.48)\end{array}$ & $\begin{array}{c}7.62 \\
(3.09)\end{array}$ \\
\hline \multirow[t]{2}{*}{$\begin{array}{c}\text { No- } \\
\text { dominance } \\
\text { pairs }\end{array}$} & Chose cheap bid & $73.02 \%$ & $\begin{array}{l}6532.87 \\
(845.66)\end{array}$ & $\begin{array}{c}1539.01 \\
(1083.70)\end{array}$ & $\begin{array}{l}1109.30 \\
(793.87)\end{array}$ & $\begin{array}{l}1177.50 \\
(851.97)\end{array}$ & $\begin{array}{c}874.83 \\
(853.77)\end{array}$ & $\begin{array}{l}6.66 \\
(3.02)\end{array}$ \\
\hline & $\begin{array}{l}\text { Chose expensive } \\
\text { bid }\end{array}$ & $26.98 \%$ & $\begin{array}{l}6778.37 \\
(951.64)\end{array}$ & $\begin{array}{l}1230.16 \\
(802.90)\end{array}$ & $\begin{array}{l}1457.90 \\
(903.74)\end{array}$ & $\begin{array}{l}1098.93 \\
(713.51)\end{array}$ & $\begin{array}{l}1222.75 \\
(788.89)\end{array}$ & $\begin{array}{l}7.56 \\
(3.41)\end{array}$ \\
\hline
\end{tabular}


Figure 1. Materials used in Experiments 1a and 1b. Participants in Experiment 1a received the table below excluding the second column (price) and were asked to choose the bids they find qualified to proceed to the next stage. Participants in Experiment $1 \mathrm{~b}$ received the full table including column 2 (price) and were asked to choose the winning bid.

\begin{tabular}{|c|c|c|c|c|c|c|c|}
\hline & $\begin{array}{l}\text { The bid's price. } \\
\text { (In millions). } \\
\text { (Exp. lb only) }\end{array}$ & $\begin{array}{c}\text { The bidder has } \\
\text { built } 2 \text { projects, at } \\
\text { a cost of } 12.5 \\
\text { million each, } \\
\text { during } 2010 \text { - } \\
2011 .\end{array}$ & $\begin{array}{l}\text { The bidder employs } \\
\text { a construction } \\
\text { engineer with } 8 \\
\text { years experience. }\end{array}$ & $\begin{array}{l}\text { The bidder is officially } \\
\text { registered as } \\
\text { "unlimited". }\end{array}$ & $\begin{array}{l}\text { The bidder employs a } \\
\text { physician with } 10 \\
\text { years of seniority, who } \\
\text { completed a residency } \\
\text { in pediatric oncology. }\end{array}$ & $\begin{array}{c}\text { The bidder must } \\
\text { submit a } \$ 25,000 \\
\text { bid bond valid } \\
\text { until } 6 / 1 / 2012 .\end{array}$ & Comments \\
\hline Bid A & 17.8 & V & See comments & V & $\mathrm{V}$ & $\mathrm{V}$ & $\begin{array}{l}\text { According to the certification } \\
\text { attached, the engineer has } 6 \\
\text { years and } 8 \text { months of } \\
\text { experience. }\end{array}$ \\
\hline Bid B & 18.9 & $\mathrm{~V}$ & $\mathrm{~V}$ & $\mathrm{~V}$ & See comments & $\mathrm{V}$ & $\begin{array}{l}\text { Residency in general oncology } \\
\text { (completed in 1993), because } \\
\text { there were no pediatric } \\
\text { oncology residencies in Israel at } \\
\text { that time. Since then has } \\
\text { worked as a pediatric oncologist } \\
\text { in a hospital. }\end{array}$ \\
\hline Bid C & 20.3 & V & V & V & V & V & $\begin{array}{l}\text { The bid complies with the } \\
\text { requirements. }\end{array}$ \\
\hline
\end{tabular}


Figure 2. The top panel summarizes the results of Experiment 1a and presents the proportion of professionals and of lay-people who qualified the problematic bids (without price information). The bottom panel summarizes the results of Experiment $1 \mathrm{~b}$ and presents the proportion of professionals and of lay-people who chose the problematic bids as the winner (with price information).

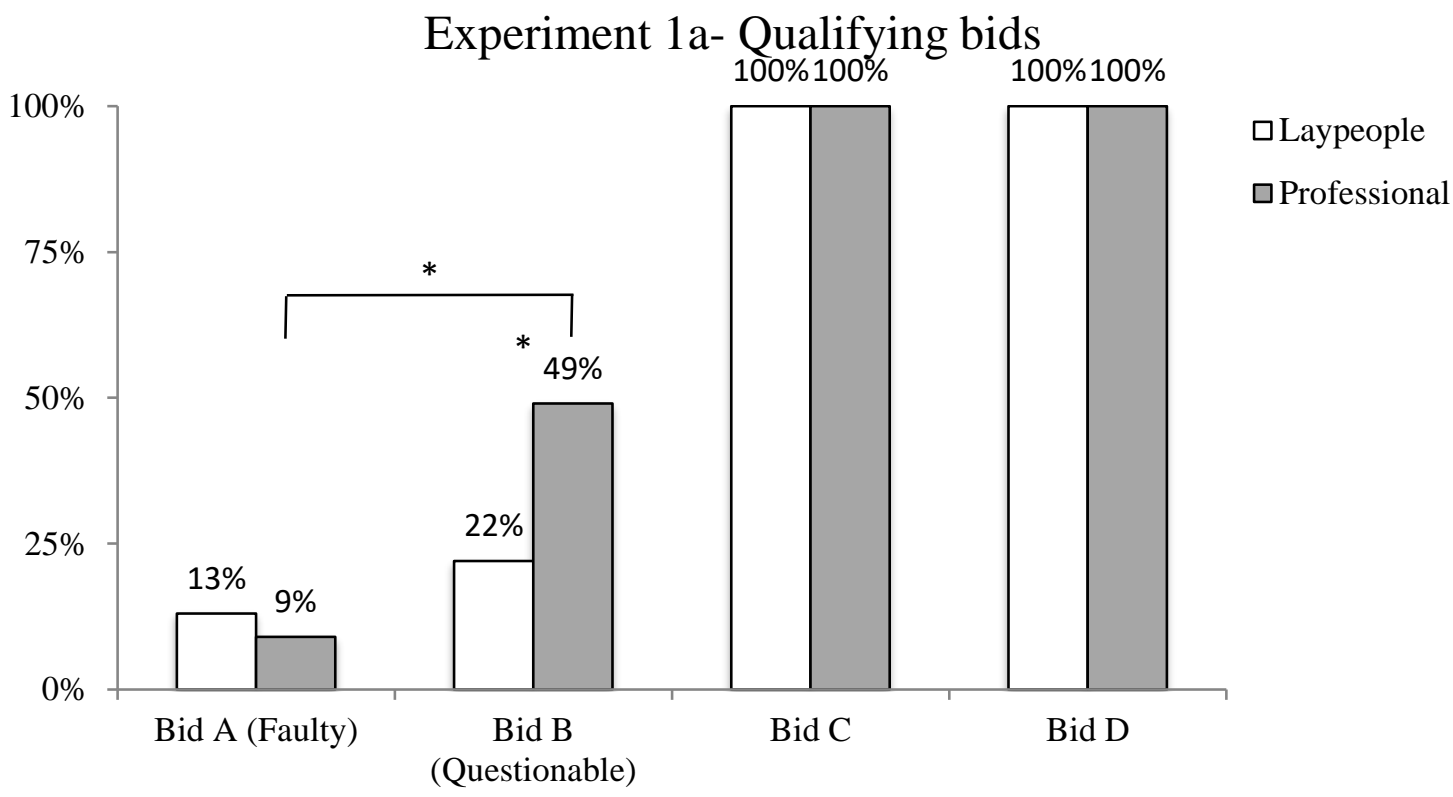

$* p<.05$

Experiment $1 \mathrm{~b}$ - Choosing the winning bid

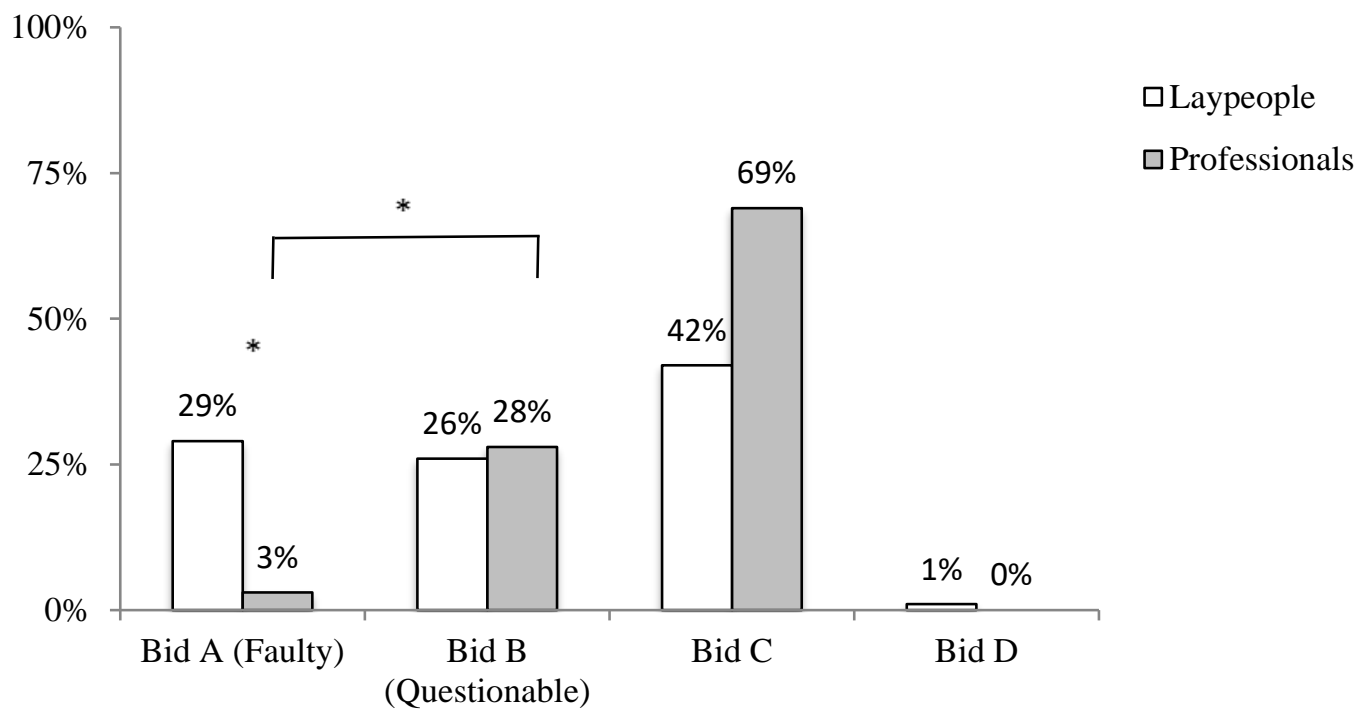

$* p<.05$ 
Figure 3: Experiment 2 - Proportion of Professionals and Lay-people who qualified the problematic bids with and without price information

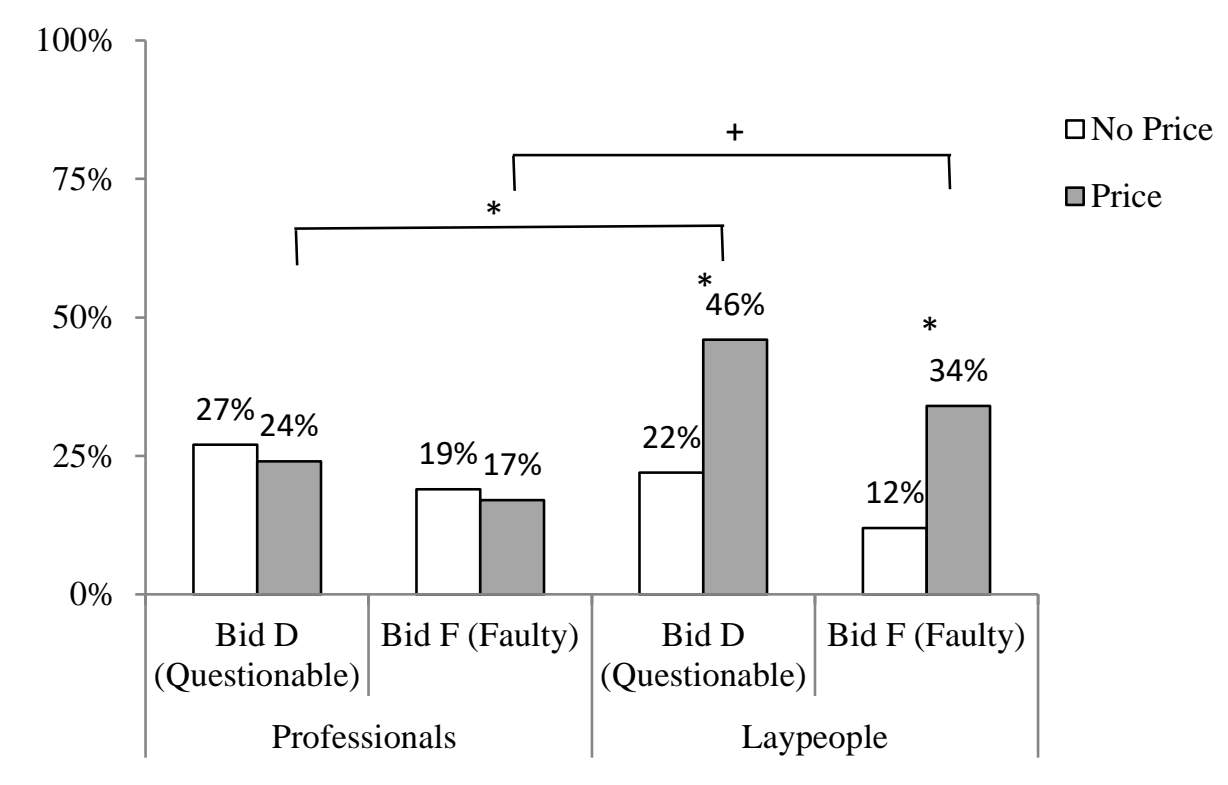

$* p<.05,+p<.1$ 
Figure 4: Experimental procedure of Experiment 3a and 3b. Participants read the instructions and choose between 40 pairs of bids (Exp 3a) or 72 pairs of bids (Exp 3b). In 20 pairs, one bid is superior to the other in terms of price and quality (i.e. low price superior quality). In 20 pairs, there is a price-quality conflict: one bid is low priced but qualitatively inferior to the other.

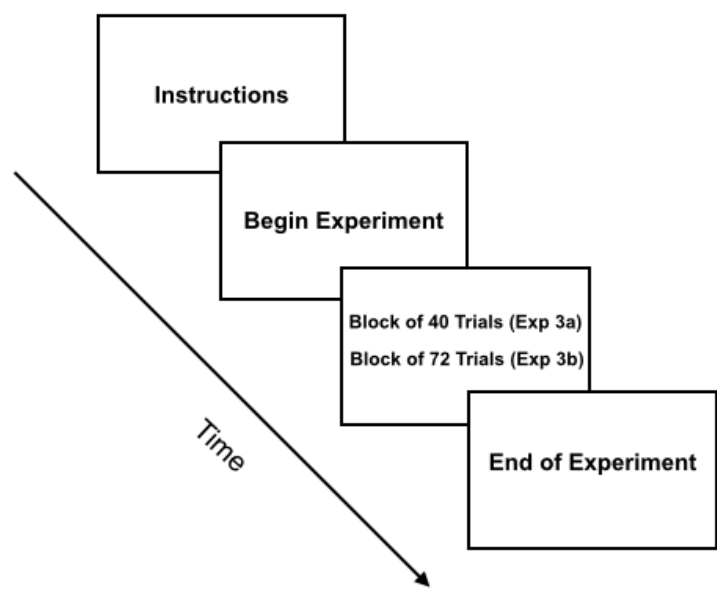

Trial Sequence

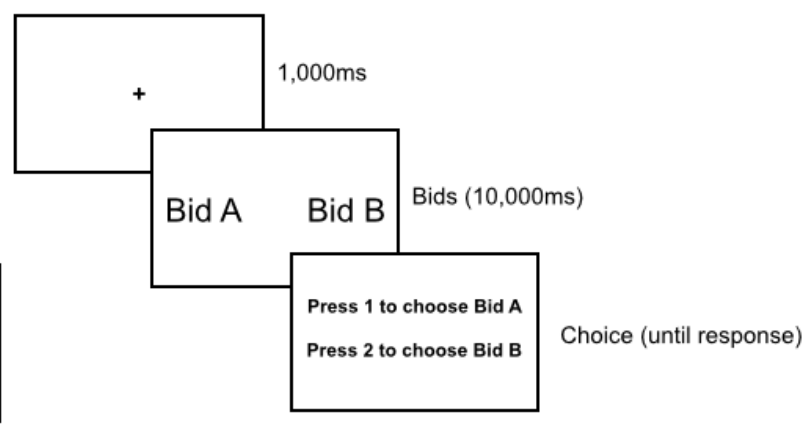


Figure 5: An example of creation of areas of interest (AOI). For each trial 4 areas of interest (AOI's) were drawn. 2 AOI's for each bid (AOI of bid), and 2 for each criterion (AOI of a criterion). In the following example, the yellow and red AOI's are AOI's of bid 1 and the blue and green AOI's are AOI's of bid 2. The yellow and blue AOI's are AOI's of the price criterion and the red and green AOI's are the AOI's of the quality criterion. For each trial we recorder the fixation duration on each of the presented AOI's.
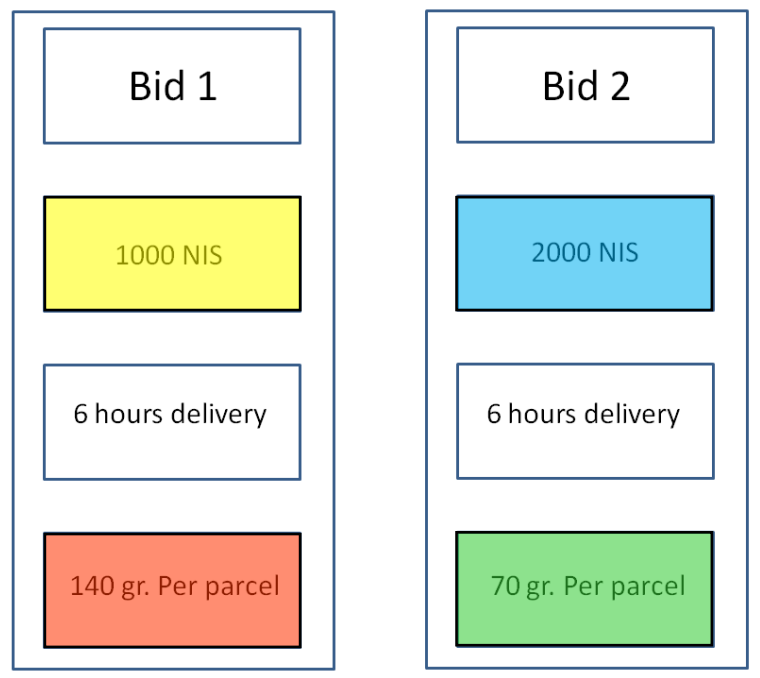
Figure 6. Different presentation formant used in Experiment 3b (from left to right: horizontal frame setting, no frame setting, and vertical frame setting)
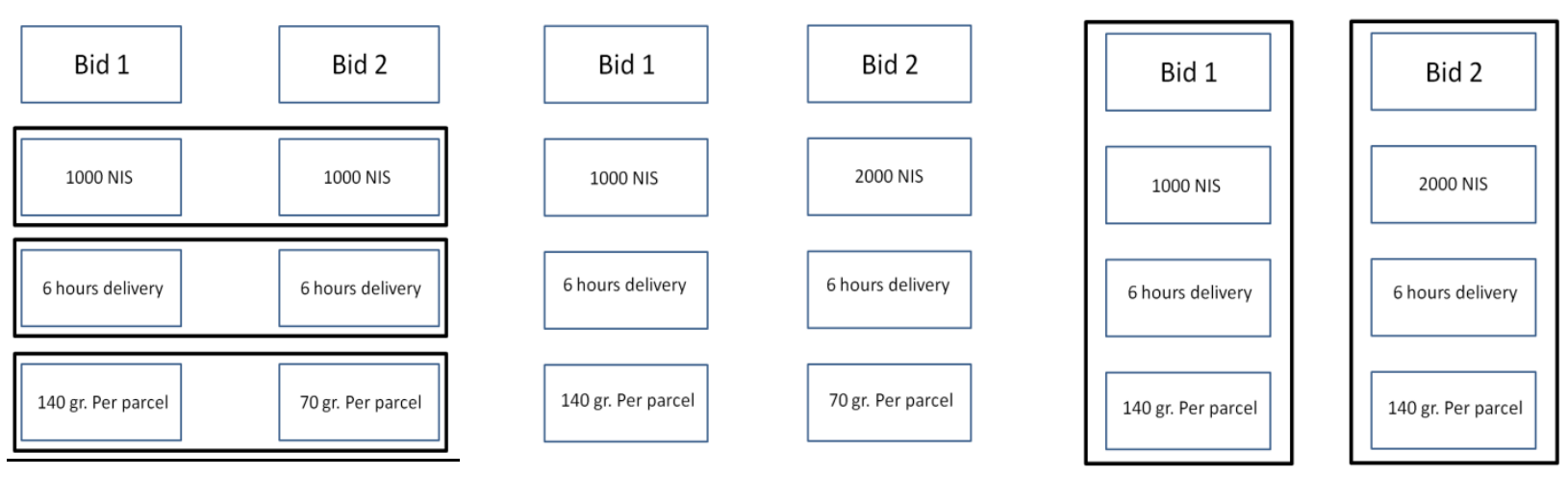
Figure 7: Experiment 4 - Percentages of Professionals and Lay-people who qualified the problematic bids under high and low accountability conditions.

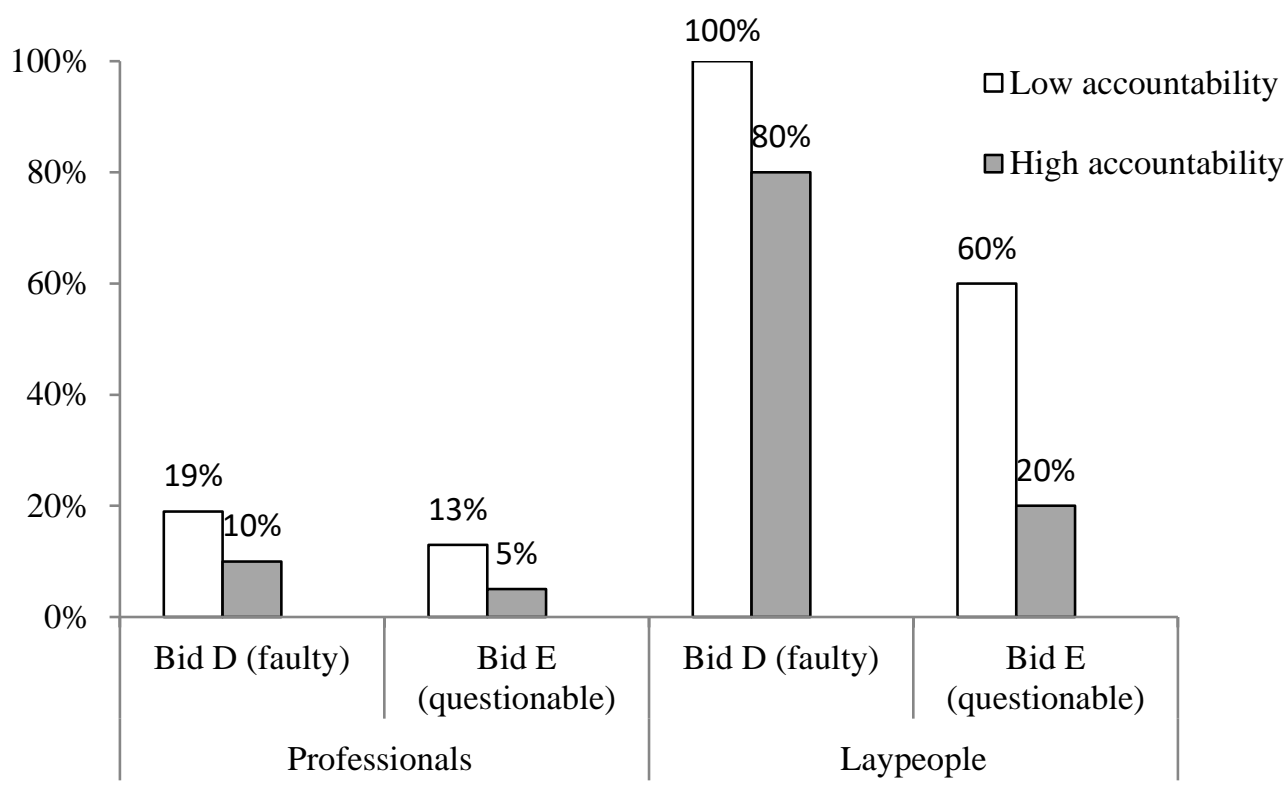

